\title{
What determines financial development?
}

\author{
Yongfu Huang
}

Discussion Paper No. 05/580

December 2005

Department of Economics

University of Bristol

8 Woodland Road

Bristol BS8 1TN 


\title{
What determines financial development?*
}

\author{
Yongfu Huang ${ }^{\dagger}$ \\ Department of Economics, University of Bristol \\ 8 Woodland Road, Bristol BS8 1TN
}

December 7, 2005

\begin{abstract}
This paper studies the fundamental determinants of cross-country differences in financial development. Two prominent tools for addressing model uncertainty, Bayesian Model Averaging and Generalto-specific approaches, are jointly applied to investigate the financial development effects of a wide range of variables taken from various sources. The analysis suggests that the level of financial development in a country is determined by its institutional quality, macroeconomic policies, and geographic characteristics, as well as the level of income and cultural characteristics.

Keywords: Financial development; Principal component analysis; Model uncertainty; Bayesian Model Averaging; General-to-specific approach
\end{abstract}

JEL Classification: O16; E44

${ }^{*}$ I am very grateful to seminar participants at the financial development workshop held at the University of Bristol for helpful comments, and especially Jonathan Temple for his valuable supervision, comments and assistance throughout the preparation of this paper. The usual disclaimer applies.

${ }^{\dagger}$ Correspondence: Email: y.huang@bristol.ac.uk; Tel: 0044-117-928 8402; Fax: 0044$117-9288577$ 


\section{Introduction}

This paper attempts to examine systematically the factors that might account for cross-country differences in financial development. It employs two modern quantitative methods, Bayesian Model Averaging (BMA) and General-to-specific (Gets) approaches, to gauge the robustness of a selection of determinants of financial development. Special emphasis has been placed on the contributions that institutions, policy and geography may have in developing financial markets that provide funds for firms to undertake investment projects.

Firstly, take a look at some simple contrasts in the financial development experience. The United Kingdom and France have similar levels of GDP per capita, democratic institutions, and geographic characteristics in terms of latitude, access to the sea and distance from large markets. Nevertheless, they follow different legal traditions, reflected in different legal practices towards the protection of private property rights. In the 1990s the ratio of private credit to GDP in the UK $(112 \%)$ was much higher than the same ratio in France $(89 \%)$. Stock market capitalisation to GDP ratio in the UK was more than three times higher than that in France. How much of the difference in financial depth between the UK and France is due to the difference in their legal traditions and practices?

The financial development experience in Latin American countries provides an enlightening example of the possible role of macroeconomic policies in financial development given the similarities of geographic conditions, institutional development and cultural characteristics. After implementing market-oriented policies in the 1970s and establishing prudential regulations in the 1980s, Chile achieved a remarkable growth in financial intermediary development and stock market capitalisation, and has been regarded as the financial leader in Latin America since the mid-1980s. In the 1990s both the ratio of liquid liabilities to GDP and the ratio of private credit to GDP in Chile were fifty percentage points higher than those of Brazil, the second best country in the region. Stock market capitalisation as a fraction of GDP in Chile in the 1990s was 78\%, at least three times larger than that in any other Latin American country. How much of the success of Chilean financial 
development is due to better macroeconomic policies?

In the 1990s the ratio of credit issued to the private sector to GDP in Canada was 94\%, more than four times higher than that in Mexico of $23 \%$. Stock market capitalisation as a fraction of GDP in Canada in 1990s was $65 \%$, more than two times higher than in Mexico (31\%). Canada and Mexico share a number of similarities in terms of geographic endowments and institutional development. More specifically, both of them have access to the sea, have a long border with the biggest developed country, have a large land area and a democratic political system, etc. However, among others Canada and Mexico apparently differ in income level and latitude, which is associated with tropical cash crops in Mexico and grain in Canada. How much of the difference in financial depth between Canada and Mexico is due to the difference in income level and how much is due to their geographic endowment, and its effects on institutions?

Exploring what determines financial development has become an increasingly significant research topic in recent years. Examples are La Porta et al. (1997, 1998), Beck et al. (2003), Rajan and Zingales (2003) and Stulz and Williamson (2003) to mention a few. La Porta et al. $(1997,1998)$ have made a significant contribution to this topic concerning the legal determinants of financial development. By applying the settler mortality hypothesis of Acemoglu et al. (2001) to financial development, Beck et al. (2003) address how institutions matter for financial development. Rajan and Zingales (2003) interest groups theory argues that politics matter for financial development. Stulz and Williamson (2003) illustrate that culture matters although it may be tempered by openness. As to the role of policy, among others Huang and Temple (2005) study the importance of trade openness, whilst Chinn and Ito (2005) focus on the effect of financial openness.

Besides this, there is a large body of research aiming to identify the determinants of financial development, ranging from some emphasizing macroeconomic factors such as inflation, the income level (in terms of GDP per capita) and the saving rate, to others stressing institutional factors and geographic factors. Since the relevant economic theories provide limited guidance on the specification of a cross-country regression for financial development, it is not clear which of these factors, acting relatively independently, plays the 
primary role in determining financial development when they are all taken into consideration. Formally speaking, there is a model uncertainty problem concerning which variables should be included in the model to capture the underlying data generating process.

When facing a situation where a vast literature suggests a variety of economic policy, political and institutional factors as determinants of longrun average growth rates, Levine and Renelt (1992) raised a concern over the robustness of existing conclusions in cross-section growth regressions. They found that only a few variables can be regarded as robust determinants of growth and almost all results are "fragile". They suggested applying a version of "extreme bounds analysis" to the problem of model uncertainty. Motivated by this influential work, Sala-i-Martin (1997a, b), Fernandez et al. (2001), and Sala-i-Martin et al. (2004) are significant works among others that have investigated the contributions of various factors to cross-country growth. These works have emphasized the BMA methods as a potential technique for addressing model uncertainty.

Empirical research on the determinants of financial development encounters a similar model uncertainty problem to that on economic growth. This paper is the first attempt to study extensively the structural determinants of financial development using a large array of variables, by jointly applying BMA and the so-called LSE general-to-specific modelling approach (Gets), which is another modern method aiming to recover the true data-generating process. The Gets method has been recently developed and advocated by David Hendry and other practitioners (Hoover and Perez, 1999; Krolzig and Hendry, 2001 and Hendry and Krolzig, 2005 for example). To date, BMA and Gets have become more and more popular for the purpose of model selection, although the theory of econometric model selection is still underdeveloped.

Not only will this paper look at each individual factor, but it also pays special attention to the roles of institutions, policy and geography in the process of financial development ${ }^{1}$. There has been substantial research on the role of institutions, policies and geography in the process of economic

\footnotetext{
${ }^{1}$ The 39 potential determinants considered for this analysis are grouped under four headings: institutions, policy, geography and others. See Section 3.3 for details.
} 
development in which much research regards institutions as the fundamental factor in long-run growth (Acemoglu et al. 2001, Dollar and Kraay 2003, Easterly and Levine 2003 and Rodrik et al. 2004). In particular, research by Easterly and Levine (2003) and Rodrik et al. (2004) highlights the dominant role of institutions over those of geography and policy. They argue that geography and policy affect economic development through institutions by influencing their quality, and the direct effect of geography and policy on development becomes weaker (or doesn't exist) once institutions are controlled for. Is this the case for financial development?

In three aspects, this paper exhibits distinct innovations and strengths. Firstly, it considers a wider assortment of economic, political, and geographic variables than any previous study. The second aspect is its joint application of the BMA and Gets procedures which combines the strengths of each method. By jointly applying two modern methods using a wide range of variables, more reliable conclusions can be expected. Thirdly, since as pointed out by Levine (2005) there is no uniformly accepted proxy for financial development currently available, this paper constructs a composite index of financial development using principal component analysis, which enables us to look at different dimensions of financial development including overall financial development, financial intermediary development, stock market development, financial efficiency development, and financial size development (usually called "financial depth").

The analyses based on the BMA and Gets procedures lead to the following findings: Institutions, macroeconomic policies and geography, when taken as groups, together with cultural characteristics and the income level of a country are significantly associated with the level of financial development. Of 39 variables taken individually, legal origins, government quality index, a trade policy index, land area and initial GDP and initial population are found to be important determinants of finanical development.

The following section provides a brief review on the origins of financial development. Section 3 includes a description of the data. Section 4 discusses the empirical strategy and is followed by the empirical results of both BMA and Gets in section 5. Section 6 summarizes the conclusions. 


\section{Potential determinants of financial development}

Research on the role of financial development in growth can be traced back at least to Schumpeter (1912) who points out the role of a country's banking system for economic development. The inherent functions of financial systems, including mobilizing savings to their highest valued use, acquiring information, evaluating and monitoring investment projects, and enabling individuals to diversify away idiosyncratic risk, have been widely believed to encourage productive investment and therefore total factor productivity ${ }^{2}$. Given the broad consensus on the substantial role of financial development in economic growth, it is of great practical importance to understand the origins of financial development. Recent years have witnessed burgeoning research in this context. This section briefly outlines the main possible determinants of financial development, including institutional factors, macroeconomic factors, geographic factors and others, that have been studied in the literature.

\subsection{Institutions}

Research on the role of institutions in financial development has been considerable, especially research on the effects of the legal and regulatory environment on the functioning of financial markets. A legal and regulatory system involving protection of property rights, contract enforcement and good accounting practices has been identified as essential for financial development. Most prominently, La Porta et al. $(1997,1998)$ have argued that the origins of the legal code substantially influence the treatment of creditors and shareholders, and the efficiency of contract enforcement. They document that countries with a legal code like Common Law tend to protect private property owners, while countries with a legal code like French Civil Law tend to care more about the rights of state and less about the rights of the masses. Countries with French Civil Law are said to have comparatively inefficient contract enforcement and higher corruption, and less well-developed financial systems, while countries with British legal origin achieve higher levels of financial development. Among others, Mayer and Sussman (2001)

${ }^{2}$ See Levine $(1997,2005)$ for a review. 
emphasize that regulations concerning information disclosure, accounting standards, permissible practice of banks and deposit insurance do appear to have material effects on financial development.

Beck et al. (2003)'s application of the settler mortality hypothesis of Acemoglu et al. (2001) to financial development is another significant work in this context. They argue that the extractive colonizers in an inhospitable environment aimed to establish institutions that privileged small elite groups rather than private investors, while the settler colonizers in more favorable environments were more likely to create institutions that supported private property rights and balanced the power of the state, therefore favouring financial development. Both the legal origin theory of La Porta et al. (1997, 1998) and Beck et al. (2003)'s application are related to colonisation, but the former is more concerned with how colonisation determines the national approaches to property rights and financial development, whereas the latter is more about the channel via which colonisation influences financial development.

The "new political economy" approach recently developed regards "regulation and its enforcement as a result of the balance of power between social and economic constituencies" (Pagano and Volpin, 2001). It centres on selfinterested policy makers who can intervene in financial markets on either overall regulation or individual cases for purposes such as career concerns and group interests. Rajan and Zingales (2003) emphasize the role of interest groups, the incumbent industrial firms and the domestic financial sector, in the process of financial development. They argue that, in the absence of openness, incumbents have strong incentives to block the development of a more transparent and competitive financial sector which undermines the incumbents' vested interests and relationships. When both trade openness and financial openness are encouraged, the incumbents have incentives to support financial development from which more funds can be sought to meet foreign competition and new rents can be generated to partially compensate their loss of incumbency.

Inspired by the above literature, Huang (2005a) studies whether political liberalisation intending to limit the influence of the elite group (or interests group) over policy making, widen suffrage in the political system 
and respect basic political rights and civil liberties is important for financial development. This work reveals that political liberalisation is typically followed by a higher level of financial development at least in the short-run. However, Huang (2005b) suggests that, once democracy has been established and enhanced, the extent of democracy may exert negative effects on the likelihood of reform aimed at financial development.

Generally speaking, institutions might have a profound impact on the supply side of financial development. The level of institutional development in a country to some extent determines the sophistication of the financial systems.

\section{$2.2 \quad$ Policy}

The policy view highlights the importance of some macroeconomic policies, openness of goods markets and financial liberalisation in promoting financial development. The significant effect of policy on financial development could be working through either the demand side or supply side of financial development.

Some major national macroeconomic policies such as maintaining lower inflation and higher investment have been documented to be conducive to financial development. Huybens and Smith (1999) theoretically and Boyd et al. (2001) empirically investigate the effects of inflation on financial development and conclude that economies with higher inflation rates are likely to have smaller, less active, and less efficient banks and equity markets. Huang (2005c) empirically investigates the existence and direction of causality between private investment and financial development on a panel dataset of 43 developing countries over the period 1970-1998. He shows positive causal effects going in both directions.

Some recent work has supported the view that policies which encourage openness to external trade tend to boost financial development (Do and Levchenko, 2004; Huang and Temple, 2005). Huang and Temple (2005) utilise the cross-country and time-series variation in openness and financial development, finding a positive effect of increases in goods market openness on financial development. 
Apart from these, research has been carried out to study the effects of financial liberalisation on financial development over the past three decades following the McKinnon-Shaw model (McKinnon, 1973; Shaw, 1973), which concludes that, while financial repression reduces the quantity and quality of aggregate investment, financial liberalisation can foster economic growth by increasing investment and its productivity. The positive link between domestic financial liberalisation and financial development is supported by evidence (World Bank, 1989) though domestic financial liberalisation is not

without risks (Demirgüç-Kunt and Detragiache, 1998). Research on the positive correlation between external financial liberalisation, especially capital account openness, and financial development is discussed in the panel data studies of Bailliu (2000) and Chinn and Ito (2005) though potential destabilizing effects may also exist. Claessens et al. (1998) present evidence that opening banking markets improves the functioning of national banking systems and the quality of financial services, with positive implications for banking customers and lower profitability of domestic banks. Laeven (2000) examines whether the liberalisation of the banking sector may help reduce financial restrictions and the external cost of capital premium, stimulating investment and financial development. Bekaert et al. (2002) provide evidence that opening up the stock market to foreign investors renders stock returns more volatile and more highly correlated with the world market return.

\subsection{Geography}

There is less work directly addressing the potential correlation between geography and financial development in comparison to that for policy and institutions. However, much research attention has been paid to the importance of geography for economic development, emphasizing three aspects in particular.

The first group is concerned with the correlation between latitude and economic development. Countries closer to the equator typically have a more tropical climate. On the one hand, research by Kamarck (1976), Diamond (1997), Gallup et al. (1999) and Sachs (2003a, b) suggests that tropical 
location may directly lead to poor crop yields and production due to adverse ecological conditions such as fragile tropical soils, unstable water supply and prevalence of crop pests. On the other hand, tropical location can be characterised as an inhospitable disease environment, which is believed to be a primary cause for "extractive" institutions (Acemoglu et al., 2001).

A second strand of research relates to countries being landlocked, distant from large markets or having only limited access to coasts and oceannavigable rivers (Sachs and Warner, 1995a, b, 1997; Easterly and Levine, 2003; Malik and Temple, 2005). As natural barriers to external trade and knowledge dissemination, geographic isolation and remoteness to some extent determine the scale and structure of external trade in which those countries engage. The countries' potential to enter a large economic market and exploit economies of scale may be limited by particular geographic circumstances. The ability to develop a competitive manufacturing sector may be constrained when some intermediate products for the manufactured goods need to be imported from distant markets. The export of a limited range of primary commodities is therefore the main feature of external trade for these countries, determining their vulnerability to external shocks.

The last strand of research focuses on the link between resource endowment and economic development. Diamond (1997) suggests that countries with a richer endowment of grains species have more potential for highyielding food crops and technological development. Isham et al. (2002) argue that a developing country's natural resource endowment affects its economic development through an unique channel, namely natural resource endowment is linked to different export structures, different export structures determine institutional capacities towards coping with external shocks and finally the institutional quality is reflected in the level of GDP per capita. Easterly and Levine (2003) argue that the natural endowment of tropics, germs and crops indirectly influences income through their impacts on institutions.

In general, geography mainly works through the demand side of financial development, although it may affect the supply side of financial development by influencing the quality of institutions. For instance, the production of particular agricultural products or primary goods, and exploitation of some 
natural resources could affect the demand for external finance.

\subsection{Other variables}

Other variables considered as determinants of financial development are economic growth, income level, population level, religious, language and ethnic characteristics and so on. Greenwood and Jovanovic (1990) and Saint-Paul (1992) document that as the economy grows, the costs of financial intermediation decrease due to intensive competition, inducing a larger scale of funds available for productive investment. The importance of income levels for financial development has been addressed in Levine (1997, 2003, 2005). In considering the banking sector development in transition economies, Jaffee and Levonian (2001) demonstrate that the level of GDP per capita and the saving rate have positive effects on the banking system structure as measured by bank assets, number, branches and employees for 23 transition economies.

Stulz and Williamson (2003) stress the impact of differences in culture, proxied by differences in religion and language, on the process of financial development. They provide evidence that culture predicts cross-country variation in protection and enforcement of investor rights, especially for creditor rights. The evidence also shows that the influence of culture on creditor rights protection is mitigated by the introduction of trade openness.

\section{The data}

This section describes the sample of countries on which this study is undertaken, and the measures of financial development and potential determinants. Appendix Table 1 contains the description and sources of these variables and Appendix Table 2 presents summary statistics.

\subsection{Samples}

Firstly, transition economies and small economies with a population of less than 500,000 in 1990 are excluded from the sample. The information on the transition economies and population size are from the World Bank Global 
Development Network Database (GDN) and the Penn World Table 6.1 due to Heston et al. (2002), respectively.

This study mainly investigates key determinants of five specific indices of financial development, which will be discussed in more depth below. For each financial development index, there are three samples on which the investigation is based: the whole sample, a developing country sample and a smaller sample for which the La Porta et al. (1998) data are available. The whole sample is the main focus of the analysis. The developing countries in the settler mortality dataset of Acemoglu et al. (2001) form the main part of the developing country sample here. Looking at the La Porta et al. (1998) sample makes it possible to examine whether differences in legal tradition, reflected in the protection of shareholders' rights and creditors' rights, determine cross-country differences in financial development. The countries included are listed in Appendex Table 3.

\subsection{Measures of financial development}

Since there is no single aggregate index for financial development in the literature, we use principal component analysis based on widely-used indicators of financial development to produce new aggregate indices.

Essentially the principal components analysis takes $N$ specific indicators and produces new indices (the principal components) $\mathrm{X}_{1}, \mathrm{X}_{2}, \ldots \mathrm{X}_{N}$ that are mutually uncorrelated. Each principal component, as a linear combination of the $N$ indicators, captures a different dimension of the data. Typically the variances of several of the principal components are low enough to be negligible, and hence the majority of the variation in the data will then be captured by a small number of indices. This paper uses the first principal component, which accounts for the greatest amount of the variation in the original set of indicators in the sense that the linear combination corresponding to the first principal component has the highest sample variance subject to the constraint that the sum-of-squares of the weights placed on each existing indicator is equal to one.

The conventional measures of financial development on which the prin- 
cipal component analysis is based are as follows ${ }^{3}$ :

The first measure, Liquid Liabilities (LLY), is one of the major indicators to measure the size, relative to the economy, of financial intermediaries, including three types of financial institutions: the central bank, deposit money banks and other financial institutions. It is calculated as the liquid liabilities of banks and nonbank financial intermediaries (currency plus demand and interest-bearing liabilities) over GDP.

The second indicator, Private Credit (PRIVO), is defined as the credit issued to the private sector by banks and other financial intermediaries divided by GDP excluding credit issued to government, government agencies and public enterprises, as well as the credit issued by the monetary authority and development banks. It measures general financial intermediary activities provided to the private sector.

The third one, Commercial-Central Bank (BTOT), is the ratio of commercial bank assets to the sum of commercial bank and central bank assets. It proxies the advantage of financial intermediaries in channelling savings to investment, monitoring firms, influencing corporate governance and undertaking risk management relative to the central bank.

Next are two efficiency measures for the banking sector. Overhead Costs $(O V C)$ is the ratio of overhead costs to total bank assets. The Net Interest Margin (NIM) equals the difference between bank interest income and interest expenses, divided by total assets. A lower value of overhead costs and net interest margin is frequently interpreted as indicating greater competition and efficiency.

The last are three indices for stock market development ${ }^{4}$. Stock Market Capitalization $(M C A P)$, the size index, is the ratio of the value of listed domestic shares to GDP.

Total Value Traded ( $T V T$ ), as an indicator to measure market activity,

\footnotetext{
${ }^{3}$ The description of these measures are heavily drawn from Demirgüç-Kunt and Levine (1996, 1999).

${ }^{4}$ Since data for the efficiency of the bond market are not available while data for the size of the bond market are mainly available for developed countries in the World Bank's Financial Structure and Economic Development Database (2005), to avoid resulting in smaller sample sizes in the principal component analysis, bond market development is not included here. A simple analysis of the determinants of bond market development (for a smaller sample) is presented in Appendix Table 8.
} 
is the ratio of the value of domestic shares traded on domestic exchanges to GDP, and can be used to gauge market liquidity on an economy-wide basis.

Turnover Ratio (TOR) is the ratio of the value of domestic share transactions on domestic exchanges to total value of listed domestic shares. A high value of the turnover ratio will indicate a more liquid (and potentially more efficient) equity market.

The data are obtained from the World Bank's Financial Structure and Economic Development Database (2005) and averaged over 1990-2001. Any measure for which fewer than three years of data are available is treated as a missing value.

Appendix Table 4 presents the eigenvalues, proportion explained, and the eigenvector of each first principal component from which the new indices of financial development are defined. It reports the sample variance of each first principal component (linear combination), the proportion of the variance in the raw data the first principal component accounts for, and the coefficient (weight) of each existing standardised measure in the linear combination.

(1) The first is a measure of overall financial development, denoted by $F D$. This is based on eight components, namely Liquid Liabilities, Private Credit, Commercial-central Bank, Overhead Cost, Net Interest Margin, Stock Market Capitalisation, Value Traded and Turnover. The first principal component accounts for $49 \%$ of the variation in these seven indicators. In Appendix Table 4 the coefficients of each financial indicator for FD indicate the negative correlations between the Overhead Cost and Net Interest Margin and $F D$, and the positive correlations between the rest and $F D$.

(2) A second measure, FDBANK, captures the extent of bank-based intermediation. It uses five indicators, Liquid Liabilities, Private Credit, Commercial-central Bank, Overhead Costs and Net Interest Margin. FD$B A N K$ accounts for $61 \%$ of the variation in these five indicators.

(3) A third measure, FDSTOCK is a measure of stock market development, based on Stock Market Capitalization, Value Traded and Turnover. FDSTOCK accounts for $66 \%$ of the variations in these financial indices.

(4) A fourth measure, FDEFF, captures financial efficiency. Four indicators of financial efficiency used are Overhead Cost, Net Interest Margin, Value Traded and Turnover. FDEFF accounts for $54 \%$ of the total varia- 
tion in these indicators. Lower values of this index indicate a higher level of financial efficiency.

(5) A fifth measure, FDSIZE, based solely on Liquid Liabilities and Stock Market Capitalization, captures the size of financial system (also called "financial depth"). The first principal component of these two measures accounts for $81 \%$ of the variation.

\subsection{The potential determinants}

Potential determinants of financial development are widely selected from various sources. To discover the structural determinants of financial development, they are either those "predetermined" like fixed factors, or those "evolving slowly over time" like some institutional factors which are averaged over 1960-89. All variables that could potentially cause serious endogeneity problems are excluded ${ }^{5}$. The candidate determinants are grouped into four categories as showed in Appendix Table 1. The problem of missing data has been addressed by using a set of fixed factors as independent variables to impute the missing data. The fixed factors used include some regional dummies, dummies for income levels and geographic factors for which we have a complete set of data. The imputation information is presented in Appendix Table 5.

\subsubsection{Institutional variables}

This analysis firstly considers legal origin dummies from the GDN due to the work by La Porta et al. $(1997,1998)$ on the legal determinants of financial development. The relevant variables are the common law legal origin dummy (COMLEG) for countries with British legal origin and a civil law legal origin dummy (CIVLEG) for countries with French, Germany and Scandinavian legal origins. Two variables below closely related to the financial system itself are also considered ${ }^{6}$. Taken from the dataset of La Porta et al. (1998),

\footnotetext{
${ }^{5}$ Measures of financial liberalization and financial openness are not used here due to the concern that the effects of other variables on financial development may work through them.

${ }^{6}$ Accounting standards data in La Porta et al. (1998) forms another interesting variable, but this variable has to be excluded due to its limited country coverage.
} 
SRIGHT is the aggregate index for shareholders' rights ranging from 0 to 6, while CRIGHT is the aggregate index for creditors' right ranging from 0 to 4 . These variables directly measure the extent to which the government protects the rights of shareholders and creditors.

In addition, this research makes use of some general institutional indicators. POLITY2 and DURABLE are taken from the PolityIV Database (Marshall et al., 2003), and averaged over 1960-89. POLITY2 is an index of democracy, seeking to reflect government type and institutional quality based on freedom of suffrage, operational constraints and balances on executives, and respect for other basic political rights and civil liberties. It is called the "combined polity score", equal to the democracy score minus the autocracy score. The democracy and autocracy scores are derived from six authority characterics (regulation, competitiveness and openness of executive recruitment; operational independence of chief executive or executive constraints; and regulation and competition of participation). Based on these criteria, each country is assigned a democracy score and autocracy score ranging from 0 to 10 . Accordingly, POLITY2 ranges from -10 to 10 with higher values representing more democratic regimes. DURABLE is an index of political stability, using the number of years since the last regime transition or independence. The next variable is FREE, the average of the indexes of civil liberties and political rights from the Freedom House Country Survey (2003) over 1972-89. Higher ratings indicate better civil liberties and political rights such as freedom to develop views, institutions and personal autonomy apart from government. I also employ KKZ and PCI. The KKZ measure from Kaufmann et al. (1999) is a widely-used indicator of the quality of government in a broader sense, derived by averaging six measures of government quality: voice and accountability, political stability and absence of violence, government effectiveness, light regulatory burden, rule of law, and freedom from graft. The variable PCI, measuring narrowly the constraints on the executive, is derived by Henisz (2000). The last institutional variable I use is EURO1900, the percent of population that was European or of European descent in 1900, taken from Acemoglu et al. (2001).

Although missing values for EURO1900, SRIGHT, CRIGHT as well as the market share of state-owned media (discussed below) are imputed, the 
variable EURO1900 only appears in the developing country sample while the others only appear in the La Porta sample.

\subsubsection{Policy variables}

To examine whether macroeconomic policy variables explain cross-country variation in financial development, this research makes extensive use of five economic volatility indicators and three trade openness indicators. It uses output volatility and inflation volatility to capture macroeconomic mismanagement and fluctuations. The output volatility measure (SDGR) is defined as the standard deviation of the annual growth rate of real, chain-weighted GDP per capita over 1960-89 from the Penn World Table 6.1. Inflation volatility (SDPI) is defined as the standard deviation of the annual inflation rate over 1960-89 from the World Development Indicators (2004). Taken from the GDN, the volatility of the black market premium (SDBMP), volatility of the terms of trade (SDTT) and trading partners' output volatility (SDTP) are used to reflect the extent of external shocks. SDBMP is defined as the standard deviation of the annual black market premium (BMP) over 1960-89. SDTT is defined as the standard deviation of the first logdifferences of a terms of trade index for goods and services. SDTP is the standard deviation of trading partners' GDP per capita growth (weighted average by trade share).

To assess the role of trade openness, this research uses dummies for fuel, non-fuel primary goods exporting countries (EXPPRIM) and manufactured goods exporting countries (EXPMANU) from the GDN. A trade openness policy index, TOPEN, available from the database of Harvard University's Center for International Development (Gallup et al., 1999), is utilised to measure the extent of openness to external trade in the presence of government intervention over 1965-90, while the trade share proposed by Frankel and Romer (1999), denoted by CTRADE, is employed to capture natural openness to external trade. CTRADE is derived by summing up all bilateral trade with all potential trading partners from a bilateral trade equation that controls for population and land area of the home country and trading partners, the distance between any two trade partners and whether or not 
the home country is landlocked.

\subsubsection{Geographic variables}

To examine the role of geography, this study takes six regional dummies from the GDN for East Asia and Pacific countries (REGEAP), Middle East and North African countries (REGMENA), West Europe and North American countries (REGWENA), South Asian countries (REGSA), Sub Saharan African countries (REGSSA) and Latin America and Caribbean countries (REGLAC), respectively. It also uses the following two geographic variables from the GDN. The landlock variable (LANDLOCK) is a dummy value that takes the value of 1 if the country has no coastal access to the ocean, and 0 otherwise. There are 17 countries that are landlocked in the whole sample. Absolute latitude (LATITUDE) equals the absolute distance from the equator of a country. The closer to the equator the countries are, the more tropical climate they have ${ }^{7}$. Latitude has an institutional interpretation since smaller absolute latitudes are associated with more unfavorable environments, which are associated with weaker institutions according to the settler mortality hypothesis of Acemoglu et al. (2001). The land area (AREA) in square kilometers for each country, taken from Hall and Jones (1999), is in logs.

This study also makes use of three additional geographic variables. One is POP100CR from the database of Harvard University's Center for International Development. It is the 1994 share of population within $100 \mathrm{~km}$ of a coast or navigable river for a country. Another is MINDIST, based on data from Jon Haveman's International Trade website. This captures the minimum distance from three capital-goods-supplying centers in the world (USA, Japan and EU represented by Belgium). The study uses the logarithm of the minimum distance from three capital-goods-supplying centres plus one. These variables might be highly correlated with external trade and manufacturing since lack of access to coasts or ocean-navigable rivers and geographic remoteness constitute natural disadvantages to external trade. A further variable for geographic endowment is a dummy for the point source

\footnotetext{
${ }^{7}$ To some extent, absolute latitude serves as an alternative indicator for the zero-one tropical dummy in the GDN.
} 
natural resource exporting countries (RESPOINT) from Isham et al. (2002), who find that, in comparison to manufacturing exporters, and exporters of "diffuse" natural resources (e.g. wheat, rice, animals) and coffee/cocoa natural resources, the exporting countries of "point source" natural resources (e.g. oil, diamonds, plantation crops) are more likely to have severe social and economic divisions, and less likely to develop socially cohesive mechanisms and effective institutional capacities to manage shocks.

\subsubsection{Other variables}

Other variables included in this analysis are initial income (GDP90), initial population (POP90), an ethnic fractionalisation index (ETHNIC), an ethnic polarisation index (ETHPOL), a religious fractionalisation index (RELIGION), a language fractionalisation index (LANGUAGE), a European first language index (EURFRAC), and the market share of state-owned media, either TV or newspapers (MEDSHARE).

The inclusion of the level of GDP per capita in 1990 (GDP90) is stimulated by work such as Greenwood and Smith (1997) on the feedback from growth in the economy to the development of financial markets. Population size is also closely related to indexes of financial development since small countries tend to have higher ratios of liquid liabilities and private credit, having the potential to affect the overall results substantially. GDP90 and POP90, the level of the population in 1990, are from the GDN and used in logs.

The variables ETHNIC, RELIGION and LANGUAGE, taken from Alesina et al. (2003), characterise social divisions and cutural differences, as does the variable ETHPOL, which is taken from Reynal-Querol and Montalvo (2005) to capture the extent to which a large ethnic minority faces an ethnic majority in a society. The EURFRAC measure, taken from Hall and Jones (1999), is the fraction of population speaking one of the major languages of Western Europe (English, French, German, Portuguese, or Spanish) as a mother tongue. To some extent, this variable reflects not only the culture of the country, but also the history of colonisation. It is therefore closely linked to some other variables like EURO1900, CIVLEG and COMLEG. 
The market share of stated-owned media (MEDSHARE) is from Djankov et al. (2003) which shows that greater state ownership of the media is associated with less political and economic freedom, inferior governance, less developed capital markets and poor health outcomes. Djankov et al. (2003) consider two kinds of media state ownership. One is press state ownership, the market share of state-owned newspapers out of the aggregate market share of the five largest daily newspapers (by circulation), and the other is television state ownership, the market share of state-owned television stations out of the aggregate market share of the five largest television stations (by viewer). The index used here is the average of the two media state ownerships.

\section{Empirical Strategy}

This section discusses the empirical strategies for dealing with model uncertainty faced by research on the determinants of financial development, with the central focus placed on Bayesian Model Averaging and General-tospecific approaches.

As summarised in section 2, substantial research has been done to explore the origins of financial development, leading to a large number of candidate determinants. Essentially the associated theories, developed under specific settings, are not mutually exclusive, raising concern over the robustness of these candidate determinants in any cross-section regression used to explain financial development.

Usually, the uncertainty about the composition of a regression model is called "model uncertainty". To handle the model uncertainty issue, a number of econometric methodologies have been proposed and widely debated. Among others, the Extreme Bounds Analysis (EBA), Bayesian Model Averaging (BMA) and General-to-specific (Gets) are the most famous methods.

The EBA proposed by Leamer $(1983,1985)$ regards a variable to be robust if its extreme bounds lie strictly one side or the other side of zero, where the extreme bounds for the coefficients of a particular variable are defined as "the lowest estimate of its value minus two times its standard error and the highest estimate of its value plus two times its standard error, respectively". 
The interval formed by two extreme bounds constitutes the maximum scope a variable may vary in the presence or absence of other variables, and indicates the confidence one may have in the coefficient estimates.

The EBA method has been widely applied in the context of cross-section growth regression since then. A version of EBA was used by Levine and Renelt (1992) to consider alterations of the conditioning information set in a robustness analysis of cross-section growth regressions. More specifically, they include three "free" variables ${ }^{8}$, one "focus" variable and at most three "doubtful" variables in all models so as to reduce the number of regressions needed to calculate the extreme bounds. By this method, they find almost all variables can be regarded as fragile determinants of growth. Salai-Martin (1997a, b) criticizes the standard of robustness employed by Levine and Renelt (1992) as too restrictive and suggests a different version of extreme bounds analysis by saying that a variable is robust as long as $95 \%$ or more of the distribution of estimates lays one side of zero. By this methodology, relatively more variables are found to be robustly related to growth. By applying a modified version of EBA to the Levine and Renelt (1992) dataset, Temple (2000) argues that "the most common objections to EBA are either misplaced or easily taken into account by a careful presentation of the results". He also regards the EBA as "a useful means of providing information on the sensitivity of results to alternative modelling choices, including the extent of uncertainty in model specification, parameter estimates and standard errors".

The methodology of Sala-i-Martin (1997 a, b) is not Bayesian although it uses weights proportional to the likelihoods of each model. Fernandez et al. (2001) re-examine the Sala-i-Martin (1997a, b) data set using a full BMA explained below and Markov Chain Monte Carlo techniques to deal with the huge range of possible models. The full BMA of Fernandez et al. (2001) requires fully specifying the prior distribution for every parameter conditional on each possible model and calculates the average of the parameter estimates across all possible models by using corresponding posterior model probabilities as weights. Their research has produced findings in support of

\footnotetext{
${ }^{8}$ They are real GDP per capita in 1960, the primary school enrolment rate in 1960 and the average investment share of GDP during 1960-89.
} 
the conclusions of Sala-i-Martin (1997a, b). However, fully specifying the prior distribution for all potential parameters is very difficult and "essentially arbitrary" (Sala-i-Martin et al. 2004) when the number of possible regressors is large. Sala-i-Martin et al. (2004) propose a version of BMA called Bayesian Averaging of Classical Estimate (BACE), in which diffuse priors are assumed for the parameters and only one other prior, relating to the expected model size, is required. This approach has generated evidence in favour of Sala-i-Martin (1997a, b)'s original findings as well.

The third strand of research on model uncertainty is the general-tospecific modelling strategy (Gets) associated with the LSE methodology. It starts from the most general unrestricted model (GUM) which is assumed to characterise the essential data generating process (DGP), applies standard testing procedures to eliminate statistically insignificant variables and ends up with a "congruent" final model, which should be free of significant misspecification.

Recent developments in computing technology render these methods rather easy to adopt. A computer programme for the Bayesian approach to model uncertainty has been developed by Raftery (1995). A computer algorithm designed for implementing the general-to-specific approach, called PcGets, has been developed by Krolzig and Hendry (2001).

Undoubtedly, the econometric theory and methods of model selection are still underdeveloped. Although the BMA and Gets procedures have respective advantages in handling model uncertainty, neither of them is without limits and exempted from criticism. As argued by Granger and Hendry (2005) and echoed by Hansen (2005), none of the model selection methods currently available is immune from four possible conceptual errors of model selection methods: parametric vision, the assumption of a true data generating process, evaluation based on fit and ignoring the impact of model uncertainty on inference. This research chooses to jointly apply the BMA and Gets procedures to handle model uncertainty in this context. The combination of Gets and BMA analyses has the advantage of incorporating their merits while circumventing some of their limitations. In what follows, I set out the methods of BMA and Gets in more detail. 


\subsection{Bayesian Model Averaging}

The sketch of the Bayesian approach to model uncertainty in this section heavily relies on Raftery (1995), Sala-i-Martin et al. (2004) and Malik and Temple (2005).

Essentially, BMA treats parameters and models as random variables and attempts to summarise the uncertainty about the model in terms of a probability distribution over the space of possible models. More specifically, it is used to average the posterior distribution for the parameters under all possible models, where the weights are the posterior model probabilities. To evaluate the posterior model probability, the BMA uses the Bayesian Information Criterion to approximate the Bayes factors that are needed to compute the posterior model probability discussed in detail below.

Typically, the number of possible models, $2^{p}$ given $p$ candidate variables, is large. Most applications of BMA to larger datasets do not average over all possible models, but use a search algorithm to identify the subset of models with greatest relevance. The Occam's Window and Markov Chain Monte Carlo techniques can be adopted for this purpose. The Markov Chain Monte Carlo techniques developed by Hoeting et al. (1996) have the advantage of selecting variables and identifying outliers simultaneously, but require a larger sample size relative to the regressor set, and so this method will be applied in Table 1 only. The simpler version of BMA used elsewhere in this study follows Raftery (1995) which only focuses on the subset defined by the Occam's Window technique and treats all the worst-fitting models outside the subset as having zero posterior probability. Embodying the principle of parsimony ${ }^{9}$, the use of the Occam's Window technique considerably reduces the number of possible models, and in the meantime encompasses the inherent model uncertainty present. Once the Occam's Window technique excludes the relatively unlikely models, the posterior model probabilities for the well-fitting models are then calculated.

\footnotetext{
${ }^{9}$ The Occam's Window approach can be divided into two types, corresponding to two approaches. One is the symmetric Occam's Window in which models "much less likely than the most likely model" are excluded, the other is the strict Occam's Window in which the models having "more likely submodels nested within them" are excluded from the subset left in the symmetric Occam's Window (Raftery, 1995).
} 
The posterior model probability is a critical concept for BMA. Below is a brief summary on how to derive it.

We suppose there are many models, $\left\{\mathrm{M}_{1}, \ldots . \mathrm{M}_{k}\right\}$ for the data $D$. Every model is specified by a vector of $d$ unknown parameters $\boldsymbol{\theta}_{i}=\left(\theta_{i 1}, \theta_{i 2}, \ldots . . \theta_{i d}\right)$, $i=1,2 \ldots K$. These models may be nested or not. Bayesians treat the unknown parameters as random variables.

Let $\Delta$ denote a quantity of interest such as a parameter. The posterior distribution of $\Delta$ given data $D$ is derived according to

$$
P(\Delta \mid D)=\sum_{i=1}^{K} P\left(\Delta \mid D, M_{k}\right) P\left(M_{k} \mid D\right)
$$

where $P\left(M_{k} \mid D\right)$ are the posterior model probabilities, and $P\left(\Delta \mid D, M_{k}\right)$ is the posterior distribution of $\Delta$ given the data $D$ and model $M_{k}$.

The equation contains all information needed to make inference about $\Delta$, indicating that the posterior distribution of $\Delta$ given data $D$ is a weighted average of its posterior distributions given data $D$ and a specific model. The weights are the posterior model probabilities, $P\left(M_{k} \mid D\right)$, which can be obtained by Bayes' theorem,

$$
P\left(M_{k} \mid D\right)=\frac{P\left(D \mid M_{k}\right) P\left(M_{k}\right)}{\sum_{i=1}^{K} P\left(D \mid M_{i}\right) P\left(M_{i}\right)}
$$

where $P\left(M_{k}\right)$ is the prior probability of model $i(i=1,2 . . K)$, and $P\left(D \mid M_{i}\right)$ is the probability of the data given $M_{i}$, also called the integrated (marginal) likelihood for model $M_{i}$ or marginal (predictive) probability of the data given $M_{i}$.

To represent no prior preference for any model, each model will start on an equal footing, that is $P\left(M_{1}\right)=P\left(M_{2}\right)=\ldots P\left(M_{k}\right)=\frac{1}{K}$. Therefore the posterior model probabilities $P\left(M_{k} \mid D\right)$ can be rewritten as

$$
P\left(M_{k} \mid D\right)=\frac{P\left(D \mid M_{k}\right)}{\sum_{i=1}^{k} P\left(D \mid M_{i}\right)}
$$

To identify the value of $P\left(D \mid M_{k}\right)$, it is useful to compare model $M_{k}$ with 
a baseline model. A null model $\left(M_{0}\right)$ in which no independent variables are included is usually used as a baseline model ${ }^{10}$.

Let $B_{k s}$ be the Bayes factor for model $M_{k}$ against model $M_{0}$, that is

$$
B_{k 0}=\frac{P\left(D \mid M_{k}\right)}{P\left(D \mid M_{0}\right)}
$$

then,

$$
2 \log B_{k 0}=2 \log P\left(D \mid M_{k}\right)-2 \log P\left(D \mid M_{0}\right)
$$

Due to the introduction of the BIC (Bayesian Information Criterion) approximation to the Bayesian factor, " $2 \log B_{k 0}$ " can be expressed as the approximation of the difference between $B I C_{0}$ and $B I C_{k}$, the values of $B I C$ for the null model, $M_{0}$, and model $M_{k}$, respectively,

$$
2 \log B_{k 0} \approx B I C_{0}-B I C_{k}
$$

The fact that $B I C_{0}=0$ yields the approximation for the posterior probability $P\left(D \mid M_{k}\right)$, which is

$$
P\left(D \mid M_{k}\right) \propto \exp \left(-\frac{1}{2} B I C_{k}\right)
$$

The posterior model probabilities $P\left(M_{k} \mid D\right)$ can be then written as

$$
P\left(M_{k} \mid D\right) \approx \frac{\exp \left(-\frac{1}{2} B I C_{k}\right)}{\sum_{i=1}^{K} \exp \left(-\frac{1}{2} B I C_{i}\right)}
$$

At this point, we are ready to implement a systematic form of inference for different quantities of interest. For example, when the interest is one of the regression parameters being present, positive or negative, what we need to do is to sum up the posterior model probabilities for all models in which the parameter is non-zero, positive or negative. In the section on empirical results below, the output of the BMA analysis includes the posterior inclusion probabilities for variables and a sign certainty index.

\footnotetext{
${ }^{10} \mathrm{~A}$ saturated model $\left(M_{s}\right)$ in which each data point is fitted exactly can be also used as a baseline model.
} 
The posterior inclusion probability for any particular variable is the sum of the posterior model probabilities for all of the models including that variable. The higher the posterior probability for a particular variable, the more robust that determinant for financial development appears to be. For posterior inclusion probabilities greater than 0.20 , a sign certainty index rather than sign certainty probability is presented, clearly suggesting the relationship being either positive or negative.

The computational procedure for the Occam's Window technique is implemented using the bicreg software for S-Plus or $\mathrm{R}$ written by Adrian Raftery and revised by Chris Volinsky. The program used to calculate the sign certainty index is developed by Malik and Temple (2005) based on the original bicreg code.

\subsection{General-to-specific approach}

Hoover and Perez (1999) make important advances in practical modelling, like the multiple-path approach to Gets model selection. Based on these, PcGets has been developed to embody the principles of the underlying theory of general-to-specific reductions extensively discussed in Hendry (1995).

The selection of models by PcGets roughly includes three stages ${ }^{11}$ :

The first stage concerns the estimation and testing of the GUM. The GUM should be formulated carefully based on previous empirical and theoretical findings, institutional knowledge and data characteristics. The specification of the GUM should be sufficiently general with a relatively orthogonal parameterization for the $\mathrm{N}$ candidate regressors. The next step is to conduct a mis-specification test for "congruence" of the initial GUM. The congruence of the initial GUM is maintained through the selection process to ensure a congruent final model. Once the congruence of the GUM is established, pre-search reduction tests are conducted at a loose significance level. The statistically-insignificant variables are eliminated both in blocks and individually, and the GUM reformulated as the baseline for the next stage.

\footnotetext{
${ }^{11}$ The summary below is heavily drawn from Hoover and Perez (1999), Krolzig and Hendry (2001), Hendry and Krolzig (2005) and Granger and Hendry (2005).
} 
The second stage is the search process. Many possible reduction paths are investigated to avoid path-dependent selection. The terminal model emerges from each path when all reduction diagnostic tests are valid and all remaining variables are significant. At the end of the path searches, all distinct terminal models are collected and tested against their union to find an undominated encompassing contender. If a unique model results, it is selected; otherwise, the "surviving" terminal models form a union as a new starting point for reduction. The search process continues until a unique model occurs, or the union coincides with the original GUM or a previous union. If a union made up of mutually encompassing and undominated models result, PcGets employs the Bayesian Information Criterion to select the unique final model.

The third stage is the post-search evaluation. At this stage PcGets use post-selection reliability checks to evaluate the significance of variables in the final model selected in two overlapping subsamples.

Obviously, the choice of critical values for pre-selection, selection encompassing tests and sub-sample post-selections is important for the success of the PcGets algorithm. It provides two basic strategies, the liberal and conservative strategy, for the levels of significance, degree of pretesting and so on. The liberal strategy tries to equate the probability of deleting relevant and retaining irrelevant variables, whilst the conservative strategy tries to reduce the chance of retaining irrelevant variables. The choice of different strategies hence affects the chance of either retaining irrelevant variables or dropping relevant variables. Throughout the paper, PcGets is conducted with a more liberal strategy than the default setting of the "liberal strategy" as presented in the Appendix Table $6^{12}$, aiming to keep all promising variables in the final model. The final conclusion is then based on the intersection of the BMA and PcGets results.

\footnotetext{
${ }^{12}$ Since any variable removed at the presearch stage is permanently eliminated, the $\mathrm{F}$ presearch testing (top-down) at step 1 in the "liberal strategy" default setting has been increased from 0.75 to 1 , so as not to risk omitting any potential factor which might not be significant in the GUM.
} 


\section{Empirical results (I): Overall financial develop- ment}

This section begins studying the determinants of various indexes of financial development. The BMA and Gets methods are applied and compared on three different samples (the whole sample, the developing country sample and the La Porta sample) for each index. This section, the central contribution of this analysis, studies the determinants of overall financial development (FD). Section 6 is concerned with the determinants for four specific indexes of financial development, followed by a study of the determinants of bond market development.

\subsection{Some stylized facts}

As a starting point, it might be useful to look at some stylized facts on the links between some important institutional, policy and geographic variables and FD. These figures are based on the whole sample.

Figure 1 presents two scatter plots for the links between institutions and financial development. Better institutional quality, captured by KKZ, and a more democratic regime, captured by POLITY2, are associated with an increase in FD. The trade policy index denoted by TOPEN and FrankelRomer trade share denoted by CTRADE are positively related to FD in Figure 2. The upper chart of Figure 3 indicates that countries closer to the main world market centers achieve a higher level of FD, while the lower chart shows that financial markets in countries further from the equator are relatively more advanced.

Figure 4 portrays the evolution of averaged liquid liability (LLY) over 1960-2003 by different country groups. Note from the upper-left chart that countries in all income groups experienced an increase in LLY, though higher-income countries remain at a higher level of financial development than lower-income countries throughout. The upper-right chart shows considerable differences in averaged LLY between manufactured goods exporting countries and primary goods exporters in which the latter remain at lower levels or at least partially financial repressed. The lower-left chart shows that the level of LLY in West Europe and North American countries 
was much higher and more stable than that in other country groups. The development process of LLY in East Asia and Pacific countries was much more pronounced relative to that in any other country group. In the last chart, the development performance of LLY in common law countries was in general much more gradual with the whole process stretching over four decades compared to that in civil law countries, which experienced surges in the 1970s and late 1990s, but a decline in the late 1980s.

The figures above have shown some interesting facts on the determinants of FD. However, a clear conclusion on the robustness of any variable presented cannot be readily drawn. The task of the subsequent section is to examine these links systematically.

\subsection{What are the main determinants of FD?}

As mentioned in the introduction, much research regards institutions as the fundamental factor in long-run growth, and some even argue that the only effect of geography and policy on development is via institutions (Acemoglu et al., 2001; Dollar and Kraay, 2003; Easterly and Levine, 2003; and Rodrik et al., 2004). Before proceeding to study the main determinants of overall financial development (FD), this section starts by testing the hypothesis of whether any of three determinants (institutions, policy and geography), considered as a whole, dominates the other two.

Table 1 reports the BMA results for determinants of FD, which is measured over 1990-99, for 64 countries in the whole sample. All possible explanatory variables are grouped into 4 blocks in the order of "other" variables, geographic variables, policy variables and institutional variables. In addition to including the "other" variables, the models 1-3 include any two of the three blocks (geographic variables, policy variables and institutional variables) to examine the combined effects of any two types of determinants on $\mathrm{FD}^{13}$.

The BMA analysis yields posterior inclusion probabilities (either "PIPs" or " $M C 3$ " $)^{14}$, the total posterior model probabilities for the set of mod-

\footnotetext{
${ }^{13}$ The effect of institutions, policy or geography on financial development is also examined in isolation. The results are not reported here, but are available from the author.

${ }^{14} \mathrm{MC} 3$ is essentially a shorthand for the Markov Chain Monte Carlo technique, which
} 
els which include a given variable of interest, and the sign certainty index ("Sign") of a relationship discussed above. The PIPs are the posterior inclusion probabilities calculated by using Occam's window to select models due to Raftery (1995). A sign certainty index is provided where the PIPs are above 0.2 . The $M C 3$ denotes the posterior inclusion probabilities computed by using the Markov Chain Monte Carlo techniques due to Hoeting et al. (1996), which conduct variable selection and outlier identification simultaneously. Any $M C 3$ greater than 0.2 is in bold.

Looking at the first block of "other" variables across models, we note that initial income, GDP90, appears to be important in almost all models with a high posterior probability of inclusion, meaning that the level of GDP per capita is fundamental in explaining the cross-country variation in FD. Other variables in this block exhibit varying explanatory power for FD. Model 1 and 2 present the effect of geography on FD when policy and institutions are controlled for, respectively. The effect of geography on FD doesn't seem to disappear when the institutional variables are present, implying that the usual claim that geography works through institutions is not neccesarily true in this context. The two BMA methods show that two regional dummies (REGSSA and REGLAC) appear to be closely related to FD, meaning a number of developing countries in these regions are associated with higher levels of financial development in 1990s, conditional on other variables. The regional dummy REGEAP and land area (AREA) also appear to be important predictors of FD when institutions are controlled for. Similarly, policy has a significant effect on FD in the presence of geography and institutions (model 1 and 3). Among others, at least EXPPRIM is significant in both cases. Neither does the usual claim that policy works through institutions by affecting their quality apply to this context. Model 2 and 3 show that the role of institutions is not altered when geography and policy are controlled for. Note that most of the institutional variables appear to be significant predictors of FD, in particular, the KKZ (governance index) and PCI (political constraints index) have a posterior probability of inclusion close to 1.

is only applied in this table as a robustness test. 
Overall, Table 1 has demonstrated that geography, institutions and policy as a group are all important in the process of financial development, although their effects may be picked up by varied predictors when conditioning on other factors is in place. These results clearly suggest that it would be more appropriate to include all of them in the models.

Table 2 contains a thorough study of determinants of FD by using BMA and Gets on three samples in which the above conclusion in terms of geography, institutions and policy being all important is embodied. In the whole sample, there are 64 observations together with a set of 35 potential explanatory variables in all. In the sample of developing countries there are 44 observations and a set of 35 potential explanatory variables which is different from the variable set for the whole sample by the exclusion of REGWENA and the inclusion of EURO1900. The La Porta sample has 40 observations, and it has 3 additional variables (MEDSHARE, SRIGHT and CRIGHT) on top of the variable set for the whole sample.

The BMA analysis reports posterior probabilities of inclusion (PIPs) and the sign certainty index ("Sign") discussed above. The PcGets analysis produces the coefficients and t-values for possible determinants in the final model. The PcGets also reports the residual sum of squares (RSS); the equation standard error or residual standard deviation (sigma); the squared multiple correlation coefficient $\left(R^{2}\right)$ and its values adjusted for degree of freedom $\left(R_{a d j}^{2}\right)$; the log-likelihood value and three information criteria (AIC, $\mathrm{HQ}$ and $\mathrm{SC}$ ). The output also includes three mis-specification tests (Chow test, Normality test and Heteroscedasticity test) $)^{15}$. As mentioned earlier, PcGets is conducted with a relatively liberal setting presented in Appendix Table 6. The PcGets results in Table 2 are the final models for three samples, respectively, in Appendix Table 7, which clearly shows the variables included in the GUM and in the final model.

In Table 2, the BMA analysis for the whole sample yields a subset inclusive of 4 "other" variables (GDP90, POP90, ETHPOL and EURFRAC), 2 geographic variables (REGEAP and AREA), 4 policy variables (CTRADE,

\footnotetext{
${ }^{15}$ The Chow tests are $\mathrm{F}$ tests and used to test parameter constancy. The Normality test, a Chi-squared statistic, is used to check the normality of the distribution of the residuals. The Heteroscedasticity test is for unconditional heteroscedasticity.
} 
EXPPRIM, SDBMP and SDPI) and 5 institutional variables (CIVLEG, COMLEG, DURABLE, KKZ and PCI). Given no misspecification tests reject, the PcGets analysis for the whole sample yields a subset inclusive of 3 "other" variables (GDP90, POP90, and EURFRAC), 2 geographic variables (LATITUDE and AREA), 1 policy variable (SDTT) and 3 institutional variables (CIVLEG, KKZ and PCI). Both the BMA and Gets further confirm that direct effects of institutions, policy and geography on FD exist.

The BMA and Gets analyses on the whole sample unanimously suggest 3 "other" variables (GDP90, POP90, and EURFRAC), 1 geographic variable (AREA), and 3 institutional variables (CIVLEG, KKZ and PCI) are the main determinants for FD. The results from the developing country sample and the La Porta sample ${ }^{16}$ show that RESPOINT, TOPEN and SDPI should be in the models for FD. The analysis based on the La Porta sample provides some indication that the market share of stated-owned media (MEDSHARE), shareholders' rights (SRIGHT) and creditors' right (CRIGHT) are potential predictors for overall financial development.

In general, the results from the whole sample, strengthened by the results from two subsamples, provide strong evidence in support of the view discussed earlier that geography (represented by AREA and RESPOINT), policy (captured by TOPEN and SDPI) and institutions (captured by CIVLEG, KKZ and PCI) are all important for FD. The links between FD and AREA, TOPENDIX and KKZ suggest that countries with a smaller land area, more open trade policy and stronger institutions have a higher level of financial development. The initial GDP and population level are also found to be important for FD.

In Table 1 and 2, the BMA procedure has yielded posterior probabilities of inclusion for all candidate variables. A natural question to ask is about the structure of the models, especially the models with higher explanatory power. Table 3 lists the structure of the top ten models for FD in the whole sample in terms of posterior model probabilities, serving as a concrete illustration of model selection. A noteworthy point is that all these models have more than 10 possible predictors with geographic, policy and institutional

\footnotetext{
${ }^{16}$ Many experiments suggest that the results are sensitive to the inclusion of the variable EXPMANU.
} 
and "other" variables present in all models. However, one should be aware of the dramatic model uncertainty, reflected by less than $5 \%$ posterior model probabilities for all top ten "best" models, which indicates the potential value of the BMA and Gets procedures for model selection as a systematic response to model uncertainty.

Moving on one step further, OLS regressions are used to estimate some of the best performing models in Table 4 . The best model, that is the model with highest posterior probability in Table 3, is presented in column (4). The effects of GDP90 and POP90 on FD suggest that countries with a higher income level and a larger population size have more potential to develop financial markets. The relationship between regional dummies and FD show the East Asia and Pacific countries are positively associated with FD. The effect of country size on FD is negative. This is perhaps supported by the claim that land area determines transportation costs of manufactured exports, efficiency of supply chains and the flow of information and technology. A positive and statistically significant coefficient on CTRADE suggests trade openness may exert a significant role on FD. CIVLEG is found to have much stronger negative effects on FD than COMLEG, but this result should be regarded with some care. Countries with a common law legal origin in general witness better financial development as shown by the subsequent tables. The relationships between institutional factors, KKZ and PCI, and FD highlight the importance of efficient and transparent institutions, and a free and just society for FD. The effect is very strong, as shown by the standardized coefficients in the lower section of the table: a one standard deviation change in KKZ translates into more than 0.5 standard deviation of the FD measure. Stronger effects of PCI are observed.

In sum, the analysis above has suggested that institutions, policy and geography - taken as a group - jointly explain a substantial proportion of the variation in FD. When taken individually, at least AREA, TOPEN, CIVLEG, COMLEG, KKZ, PCI, GDP90 and POP90 are found to have significant influences on FD measure. 


\section{Empirical results (II): Specific financial devel- opments}

This section turns to study briefly the determinants of four specific indexes for financial development derived by using principal component analysis, namely, financial intermediary development (FDBANK), stock market development (FDSTOCK), financial efficiency development (FDEFF) and financial size development (FDSIZE). Bond market development (FDBOND) is also studied afterwards. The three samples are investigated for each index in which EURO1900 is only available for the developing country sample while SRIGHT, CRIGHT and MEDSHARE are only available for the La Porta dataset sample.

As in the previous section, the Gets model search is conducted with a relatively liberal strategy presented in Appendix Table 6.

The determinants of financial intermediary development (FDBANK) are reported in Table 5 . The whole sample has 91 observations, the developing country sample has 70 observations and the La Porta sample has 40 observations ${ }^{17}$. The BMA and Gets analyses on the whole sample suggest FDBANK is positively related to initial income. East Asia and Pacific countries, Middle East and North African countries, and South Asian countries witness relative success in financial intermediary development. MINDIST is suggested to be important as well. The trade open policy index (TOPEN) and Frankel-Romer index (CTRADE) are significantly positively signed, suggesting financial intermediary development is boosted by more open trade policies. Three institutional variables (POLITY2, KKZ and PCI) are suggested to be determinants for FDBANK, consistent with a conventional view that better institutions are associated with better financial intermediary development. The analyses based on the developing country sample and La Porta sample in general confirm the findings for GDP90, REGEAP, REGMENA, TOPEN, KKZ and PCI. In addition, the analyses from the La Porta sample show that the shareholders'right and creditors' rights may be closely related to financial intermediary development.

\footnotetext{
${ }^{17}$ Many experiments suggest that the results are sensitive to the inclusion of the variable EXPMANU.
} 
The determinants of stock market development (FDSTOCK) are reported in Table 6 . The whole sample has 81 observations, the developing country sample has 50 observations and the La Porta sample has 49 observations. The BMA and Gets analyses on the whole sample indicate that FDSTOCK is positively related to the initial population and the ethnic polarisation index, while it is negatively related to the European first language fractionalisation index (EURFRAC). East Asia and Pacific countries experience a rise in stock market development. Land area is also important for FDSTOCK. Among other policy factors, TOPEN and SDGR are almost suggested by two methods to be in the model - this finding is also supported in the developing country sample and La Porta sample. The usual claim concerning the positive impacts of open trade policy on financial development aplies here. The significantly negative effect of output volatility on FDSTOCK means that macroeconomic mismanagement might exert an adverse effect on FDSTOCK. Three institutional variables (DURABLE, KKZ and PCI) are suggested to be the main determinants for FDSTOCK. The analyses based on the developing country sample and the La Porta sample supports the idea that more open trade policies and better institutions promote stock market development.

The determinants of financial efficiency (FDEFF) are reported in Table 7. The whole sample has 79 observations, the developing country sample has 48 observations and the La Porta sample has 49 observations. Note that the lower value of FDEFF is associated with a higher level of financial efficiency development as discussed in Section 3.2. The BMA and Gets analyses on the whole sample suggest that RELIGION is significantly related to FDEFF. East Asia and Pacific countries, South Asian countries, Middle East and North African countries tend to have more efficient financial markets. Financial markets are more efficient in countries where institutional quality (captured by KKZ) is higher. The results from two subsamples show that initial GDP and population are also important for FDEFF.

The determinants of financial size development (FDSIZE), also called financial depth, are reported in Table 8. The whole sample has 73 observations, the developing country sample has 51 observations and the La Porta sample has 42 observations. The BMA and Gets analyses on the 
whole sample suggest that financial depth in a country is positively related to the initial population. The West Europe and North American countries including most developed countries seem to witnessed a decline in financial depth. Countries with a larger land area experience relatively less financial size development. Countries with a more open trade policy are found to have better financial development in terms of size. Financial depth is also associated with a stable political system (captured by DURABLE) and less political constraints on the executive (captured by PCI). Most of these findings are supported by analyses based on a developing country sample and the La Porta sample. In addition, the analyses from the La Porta sample show that financial depth might be closely related to shareholders' rights.

We now turn to the case of bond market development. Since only size measures for bond market development, bond market capitalisation, are available in the World Bank Financial Development and Financial Structure Database (2005) with incomplete data for many developing countries, the above financial development measures do not include indexes of bond market development. Appendix Table 8 presents the specific BMA and PcGets analyses for bond market development, denoted by FDBOND, which is the sum of the private and public bonds share over GDP in 1990s. The analyses are based on the La Porta sample of 35 countries subject to data availability. The results show that initial GDP level (GDP90), language fractionalisation index (LANGUAGE), East Asia and Pacific countries (REGEAP), population density in coastal area (POP100CR) and terms of trade volatility (SDTT) and governance index (KKZ) may influence bond market development. The results support previous findings in terms of institutions, policy and geography being important for financial development, but further study critically depends on the availability of additional data.

\section{Conclusions}

The level of financial development in a country is primarily determined by its institutional quality, government policies, geographic endowments, its income level and cultural characteristics. The analysis reaches this conclusion by a joint application of recently developed Bayesian Model Averaging and 
General-to-specific methods using 39 variables, which are more than any previous study. The joint application adopted here has the potential for incorporating their merits and minimising their limits, showing advantages in mitigating arbitary choices and increasing precision in model selection. Furthermore, conducted using a large variable set, the joint application is expected to produce more reliable findings.

To explore the structural causes of financial development, the variables considered here are either predetermined or evolving slowly over time. Of 39 variables selected, 8 variables (initial income, initial population, land area, open trade policy, civil law countries, common law countries, a governance index and a political constraint index) are found to be associated with financial development. The implications of the findings are interesting and may deserve further thoughts. For example, more open trade policies are associated with greater financial development, and better institutional quality and higher levels of civil liberties and political rights are also associated with higher levels of financial development. The finding that the legal origins influence financial development supports the emphasis on legal determinants of financial development of La Porta et al. (1998).

Admittedly, the selection of variables can never be exhaustive although the number of economic, political, and geographic variables included is much more than in any previous research. This highlights the significance of placing emphasis on the role of institutions, policy and geography in financial development. The institutions, policy, geography, income level and cultural characteristics in a country constitute the economic environment in which entrepreneurs make decisions for their investment projects and external financing, consumers decide on consuming and saving, and the financial intermediaries channel the funds from savers to borrowers. Essentially, good institutional quality leads to the efficient supply of external finance while illfunctioning institutions as well as particular cultural characteristics mainly form structural impediments to the supply of external finance. On the demand side, sound economic policies, industrialisation and economic growth mainly stimulate the demand for more and cheaper credit. So does an advantageous geographic endowment, which facilitates external trade and manufacturing. On the contrary, macroeconomic mismanagement could dis- 
courage the demand for external finance. Adverse geographic characteristics may become structural impediments to demand. The fundamental roles of institutions, policy and geography on financial development appear on either the demand side or supply side of financial development.

Findings on institutions, policy and geography as a whole being all important for financial development have significant implications for developing financial markets. The significant effects of the structural factors which are relatively time-invariant means that any effort of the government to better institution quality, implement more open trade and sound macroeconomic policies, and improve geographic infrastructure can stimulate financial development in the long run. Further research, as in Abiad and Mody (2005), is needed to explore what causes governments to undertake financial reforms aimed at financial development.

\section{References}

[1] Abiad, A. and A. Mody (2005), "Financial reform: What shakes it? What shapes it?" American Economic Review, 95: 66-88.

[2] Acemoglu, D., S. Johnson, and J. Robinson (2001), "Colonial origins of comparative development: An empirical investigation", American Economic Review, 91: 1369-1401.

[3] Alesina, A., A. Devleeschauwer, W. Easterly and S. Kurlat (2003), "Fractionalization", Journal of Economic Growth, 8(2): 155-94.

[4] Bailliu, J. N. (2000), "Private capital flows, financial development, and economic growth in developing countries", Bank of Canada working paper no. 2000-15.

[5] Beck, T., A. Demirgüç-Kunt and R. Levine (2003), "Law, endowment and finance", Journal of Financial Economics, 70: 137-181.

[6] Bekaert, G., R. H. Campbell and R. Lumsdaine (2002), "Dating the integration of world equity markets", Journal of Financial Economics, 65(2): 203-247. 
[7] Boyd, J. H. and R. Levine and B. D. Smith (2001), "The impact of inflation on financial sector performance", Journal of Monetary Economics, 47: 221-48.

[8] Claessens, S., A. Demirgüç-Kunt and H. Huizinga (1998), "How does foreign entry affect the domestic banking market?" World Bank Policy Research working paper no. 1918.

[9] Chinn, M. D. and H. Ito (2005), "What matters for financial development? Capital controls, institutions, and interactions", NBER working paper no. 11370.

[10] Demirgüç-Kunt, A. and R. Levine (1996), "Stock markets, corporate finance and economic growth: An overview", World Bank Economic Reivew 10(2): 223-240.

[11] Demirgüç-Kunt, A. and R. Levine (1999), "Bank-based and marketbased financial systems: Cross-country comprisions", World Bank Policy Research working paper no. 2143.

[12] Demirgüç-Kunt, A. and E. Detragiache(1998), "Financial liberalisation and financial fragility", World Bank Policy Research working paper no. 1917.

[13] Diamond, J.,(1997), Guns, Germs, and Steel: The Fates of Human Societies, W.W. Norton, New York, NY.

[14] Djankov, S., C. McLiesh, T. Nenova and A. Shleifer (2003), "Who owns the media?" Journal of Law and Economics, 46(2): 341-82.

[15] Do, Q.-T. and A. A. Levchenko (2004), "Trade and financial development", World Bank Policy Research working paper no.3347.

[16] Dollar, D. and A. Kraay (2003), "Institutions, trade and growth", Journal of Monetary Economics, 32: 459-483.

[17] Easterly, W. and R. Levine (1997), "Africa's growth tragedy: Policies and ethnic divisions", Quarterly Journal of Economics 112(4): 1203-50. 
[18] Easterly, W. and R. Levine (2003), "Tropics, germs, and crops: How endowments influence economic development", Journal of Monetary Economics, 50: 3-39.

[19] Fernandez, C., E. Ley and M. Steel (2001), "Model uncertainty in crosscountry growth regressions", Journal of Applied Econometrics, 16: 563576.

[20] Freedom House (2003), Freedom House Country Survey, Available at www.freedomhouse.org.

[21] Frankel, J. A. and D. Romer (1999), "Does trade cause growth?" American Economic Review, 89: 379-98.

[22] Gallup, J. L., J. D. Sachs and A. Mellinger (1999), "Geography and economic development", CID at Harvard working paper no. 1.

[23] Granger, C.W.J. and D. F. Hendry (2005), "A dialog concerning a new instrument for econometric modeling", Econometrics Theory, 21(1): $278-97$.

[24] Greenwood, J. and B. D. Smith (1997), "Financial markets in development, and the development of financial markets", Journal of Economic Dynamics and Control, 21: 145-181.

[25] Hall, R. and C. Jones (1999), "Why do some countries produce so much more output per worker than others?" Quarterly Journal of Economics, 114: $83-116$.

[26] Haveman, J., International trade data, Available at www.eiit.org.

[27] Hansen, B. (2005), "Challenges for econometric model selection", Econometrics Theory, 21(1): 60-68.

[28] Hendry, D. F. (1995), Dynamic Econometrics, Oxford: Oxford University Press.

[29] Hendry, D. F. and H. Krolzig (2001), Automatic Econometric Model Selection Using PcGets, Timberlake Consultants Press. 
[30] Hendry, D. F. and H. Krolzig (2005), "The properties of automatic GETS modelling", Economic Journal, 115(502): 32-61.

[31] Henisz, W. J. (2000), "The institutional environment for economic growth", Economics and Politics, 12(1): 1-31.

[32] Heston, A., R. Summers. and B. Aten (2002), Penn World Table Version 6.1, Center for International Comparisons at the University of Pennsylvania (CICUP), October.

[33] Hoover, K. D., and S. J. Perez (1999), "Data mining reconsidered: Encompassing and the general-to-specific approach to specification search", Econometrics Journal, 2: 167-191.

[34] Hoeting, J., A. Raftery and D. Madigan (1996), "A method for simultaneous variable selection and outlier identification in linear regression", Computational Statistics and Data Analysis, 22: 25-70.

[35] Huang, Y. (2005a), "Will political liberalisation bring about financial development?" Bristol Economics Discussion Paper no. 05/578.

[36] Huang, Y. (2005b), "On the political economy of financial reform", unpublished $\mathrm{PhD}$ chapter.

[37] Huang, Y. (2005c), "Private investment and financial development in a globalised world", unpublished $\mathrm{PhD}$ chapter.

[38] Huang, Y. and J. R. W. Temple (2005), "Does external trade promote financial development?" CEPR discussion paper no. 5150.

[39] Huybens, E. and B.D. Smith (1999), "Inflation, financial markets and long-run real activity", Journal of Monetary Economics, 43: 283-315.

[40] Isham, J., M. Woolcock, L. Pritchett and G. Busby (2002), "The varieties of rentier experience: How natural resource export structures affect the political economy of economic growth", available at www.middlebury.edu/NR/rdonlyres/23035072-BFD1-43A1-923C99CF11831F32/0/0308.pdf. 
[41] Jaffee, D. and M. Levonian (2001), "Structure of banking systems in developed and transition economies", European Financial Management, $7(2): 161-81$.

[42] Kamarck, A. M. (1976), The Tropics and Economic Development, John Hopkins University Press, Baltimore, MD.

[43] Kaufmann, D., A. Kraay and P. Zoido-Lobaton (1999), "Aggregating governance indicators", World Bank Policy Research working paper no. 2195 .

[44] King, R. G. and R. Levine (1993), "Finance and growth: Schumpeter might be right", Quarterly Journal of Economics, 108: 717-737.

[45] Knack, S. and P. Keefer. (1995), "Institutions and economic performance: Cross-country tests using alternative institutional measures", Economics and Politics 7(3): 207-27.

[46] Krolzig, H-M. and D. F. Hendry (2001), "Computer automation of general-to-specific model selection procedures", Journal of Economic Dynamics and Control, 25: 831-866.

[47] La Porta, R., F. Lopez-de-Silanes, A. Shleifer, R. W. Vishny (1997), "Legal determinants of external finance", Journal of finance, 52(3): 1131-1150.

[48] La Porta, R., F. Lopez-de-Silanes, A. Shleifer, R. W. Vishny (1998), "Law and finance", Journal of Political Economy, 106: 1113-1155.

[49] Laeven, L. (2000), "Does financial liberalization reduce financial constraints?" World Bank Policy Research working paper no. 2435.

[50] Leamer, E. E. (1983), "Let's take the con out of econometrics", American Economic Review, 73: 31-43.

[51] Leamer, E. E. (1985), "Sensitivity analysis would help", American Economic Review, 75: 308-13. 
[52] Levine, R. (1997), "Financial development and economic growth: Views and agenda". Journal of Economic Literature, 35: 688-726.

[53] Levine, R. (2003), "More on finance and growth: More finance, more growth?" The Federal Reserve Bank of St. Louis. July/August

[54] Levine, R. (2005), "Finance and growth: Theory and evidence", in P. Aghion and S. N. Durlauf (eds.) Handbook of Economic Growth NorthHolland.

[55] Levine, R. and D. Renelt (1992), "A sensitivity analysis of cross-country growth regressions", American Economic Review, 82: 942-63.

[56] Marshall, M. G. and K. J. Taeggers (2003), Polity IV Project Country Reports, CIDUM, University of Maryland.

[57] Malik, A. and J. R. W. Temple (2005), "The geography of output volatility", CSAE working paper no. 2005-07.

[58] Mayer, C. and O. Sussman (2001), "The assessment: finance, law and growth", Oxford Review of Economic Policy, 17(4): 457-66.

[59] McKinnon, R. I. (1973), Money and Capital in Economic Development, Washington D.C. Brookings Institution.

[60] Pagano, M. and P. Volpin (2001), "The political economy of finance", Oxford Review of Economic Policy, 17(4): 502-19.

[61] Raftery, A. E.(1995), "Bayesian model selection in social research", In Sociological Methodology (Peter V. Marsden, ed.), Blackwells, Cambridge, 111-196.

[62] Rajan, R. G. and L. Zingales (1998), "Financial dependence and growth", American Economic Review, 88(6): 559-586.

[63] Reynal-Querol, M. and J. G. Montalvo (2005), "Ethnic polarization, potential conflict and civil war", American Economic Review, 95(3): 796-816. 
[64] Rodrik, D. and A. Subramanian and F. Trebbi (2004), "Institutions rule: the primacy of institutions over geography and integration in economic development", Journal of Economic growth, 9: 131-165.

[65] Sachs, J. D. (2003a), "Institutions don't rule: Direct effects of geography on per capita income", NBER working paper no. 9490.

[66] Sachs, J. D. (2003b), "Institutions matter, but not for everything", Finance and Development, 40(2).

[67] Sachs, J., A. Warner (1995a), "Economic reform and the process of global integration", Brookings Papers on Economic Activity 1: 1-95.

[68] Sachs, J., A. Warner (1995b), "Natural resource abundance and economic growth", NBER working paper no. 5398.

[69] Sachs, J., A. Warner (1997), "Fundamental sources of long-run growth", American Economic Review Papers and Proceedings 87: 184-188.

[70] Sala-i-Martin, X. (1997a), "I have just run two million regressions," American Economic Review 87(2): 178-183.

[71] Sala-i-Martin, X. (1997b), "I have just run four million regressions", unpublished typescript, Economic Department, Columbia University.

[72] Sala-i-Martin, X., G. Doppelhofer and R. Miller (2004), "Determinants of long-run growth: A Bayesian Averaging of Classical Estimates (BACE) approach", American Economic Review, 94(4): 813-35.

[73] Schumpeter, J. A. (1912), The Theory of Economic Development, Harvard University Press, Cambridge MA.

[74] Shaw, E. S. (1973), Financial Deepening in Economic Development, New York, Oxford University Press.

[75] Stulz, R. M. and R. Williamson (2003), "Culture, openness, and finance", Journal of financial Economics, 70: 313-349.

[76] Temple, J. (2000), "Growth regressions and what the textbooks don't tell you", Bulletin of Economic Research, 52(3): 181-205. 
[77] World Bank (1989), World Development Report, New York, Oxford University Press. 


\section{Figure 1: Scatter plots of institutions and financial development}
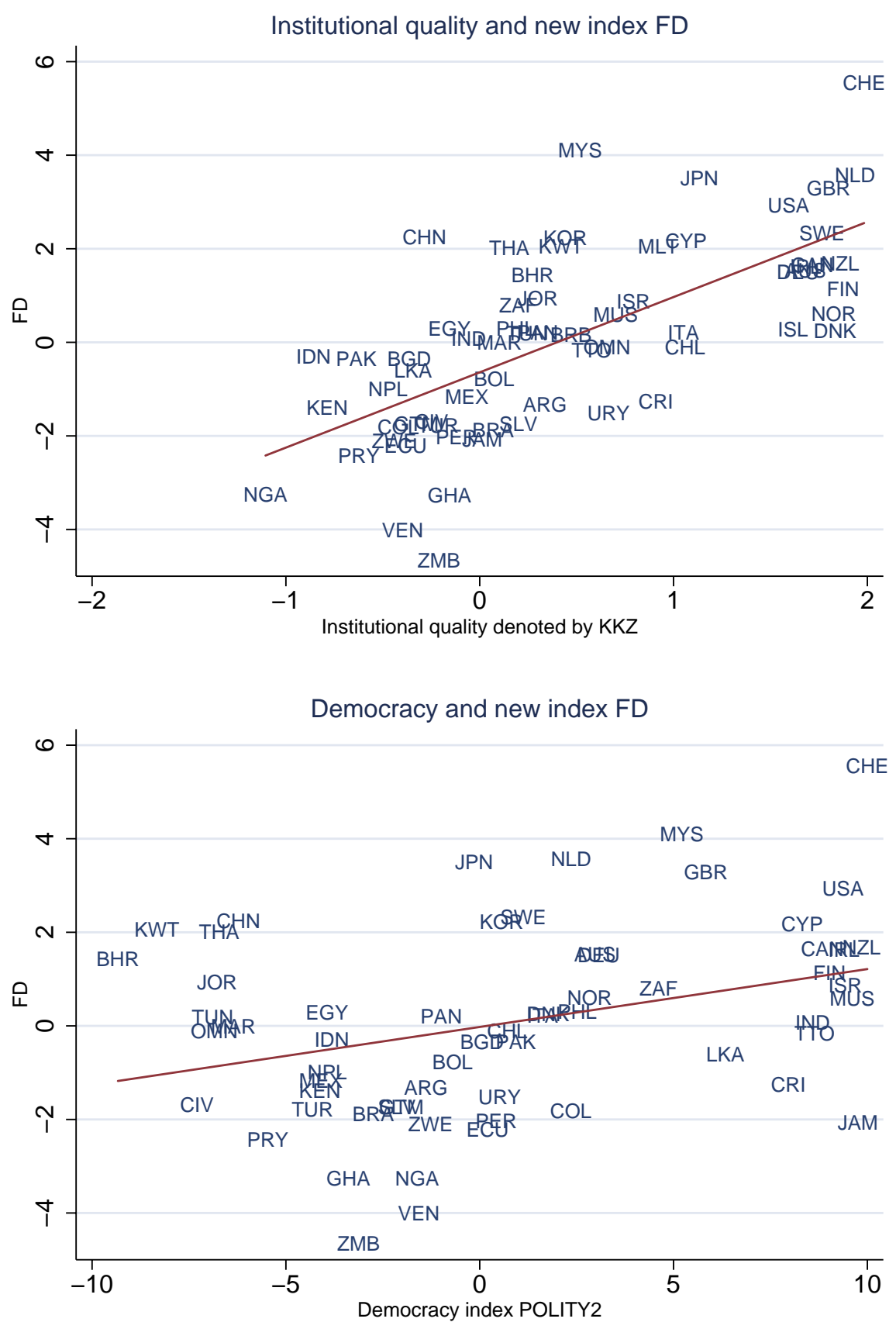

Note: Variables and data sources are described in Appendix Table 1. These figures show scatter plots of the institutional quality denoted by KKZ, and the democracy index POLITY2, against the new index FD. 
Figure 2: Scatter plots of policy and financial development

Trade policy and new index FD
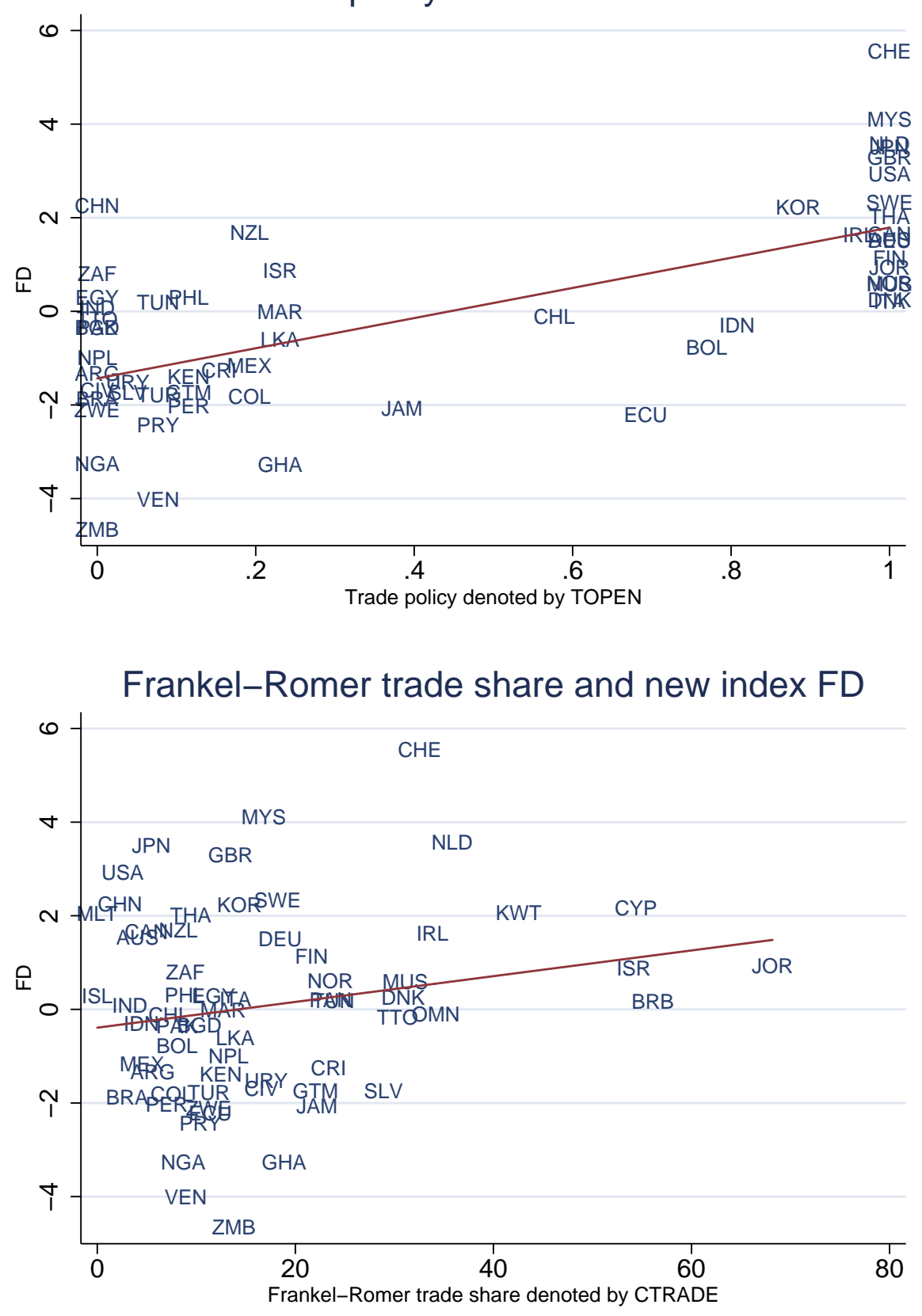

Note: Variables and data sources are described in Appendix Table 1. These figures show scatter plots of the trade policy index from Gallup et al. (1999), and the trade share constructed by Frankel and Romer (1999), against the new index FD. 


\section{Figure 3: Scatter plots of geography and financial development}
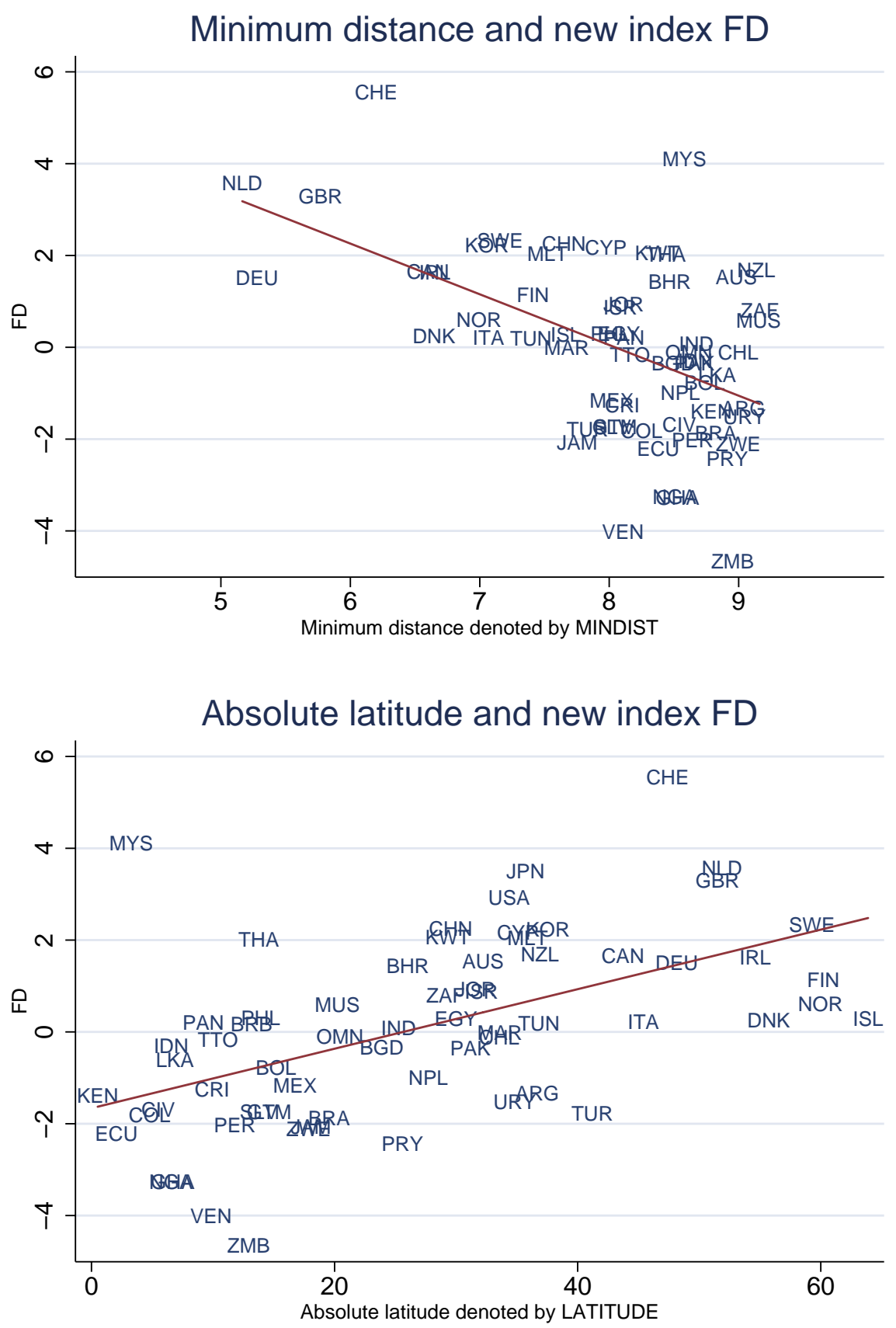

Note: Variables and data sources are described in Appendix Table 1. These figures show scatter plots of the logarithm of minimum distance, and the absolute latitude, against the new index FD. 


\section{Figure 4: Averaged Liquid liability by different country group over 1960-2003}
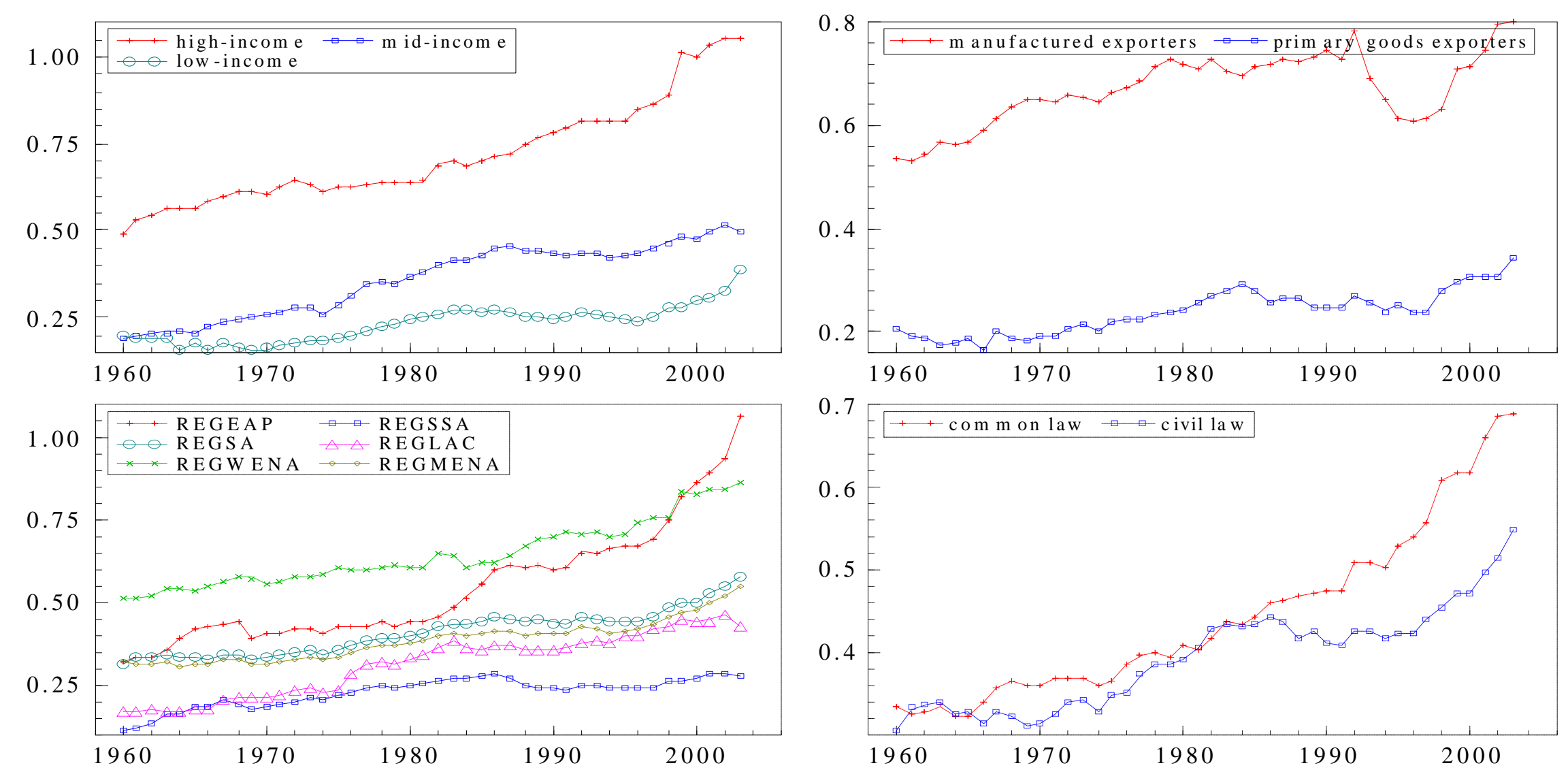

Note: Variable descriptions are from Appendix Table 1. These figures plot the averaged liquid liabilities by different income groups in the upper-left chart, different exporting countries in the upper-right chart, different regions in the lower-left chart and countries with different law traditions in the lower-right chart over 1960-2003. 
Table 1. Determinants of FD by using BMA.

\begin{tabular}{|c|c|c|c|c|c|c|c|c|c|}
\hline Sample & \multicolumn{3}{|c|}{ Whole } & \multicolumn{3}{|c|}{ Whole } & \multicolumn{3}{|c|}{ Whole } \\
\hline Countries & & 64 & & & 64 & & & 64 & \\
\hline Model & & 1 & & & 2 & & & 3 & \\
\hline Variable & PIPs & Sign & MC3 & PIPs & Sign & MC3 & PIPs & Sign & MC3 \\
\hline CONSTANT & 1.000 & $(-)$ & & 1.000 & $(-)$ & & 1.000 & $(-)$ & \\
\hline GDP90 & 0.466 & $(+)$ & 0.342 & 0.941 & $(+)$ & 0.488 & 0.744 & $(+)$ & 0.689 \\
\hline POP90 & 0.000 & & 0.026 & 0.969 & $(+)$ & 0.839 & 0.941 & $(+)$ & 0.517 \\
\hline ETHPOL & 0.004 & & 0.039 & 0.649 & $(+)$ & 0.070 & 0.906 & $(+)$ & 0.035 \\
\hline ETHNIC & 0.000 & & 0.028 & 0.014 & & 0.962 & 0.000 & & 0.333 \\
\hline RELIGION & 1.000 & $(+)$ & 0.029 & 0.056 & & 0.071 & 0.099 & & 0.029 \\
\hline LANGUAGE & 0.000 & & 0.056 & 0.036 & & 0.995 & 0.000 & & 0.962 \\
\hline EURFRAC & 0.000 & & 0.992 & 0.706 & $(-)$ & 0.040 & 0.982 & $(-)$ & 0.089 \\
\hline REGEAP & 0.186 & & 0.132 & 0.726 & $(+)$ & 0.958 & & & \\
\hline REGMENA & 0.314 & $(+)$ & 0.176 & 0.006 & & 0.060 & & & \\
\hline REGSA & 0.186 & & 0.110 & 0.053 & & 0.037 & & & \\
\hline REGSSA & 0.879 & $(-)$ & 0.946 & 0.642 & $(-)$ & 0.049 & & & \\
\hline REGLAC & 0.872 & $(-)$ & 0.942 & 0.385 & $(-)$ & 0.071 & & & \\
\hline REGWENA & 0.204 & $(-)$ & 0.175 & 0.036 & & 0.094 & & & \\
\hline LANDLOCK & 0.000 & & 0.065 & 0.003 & & 0.208 & & & \\
\hline LATITUDE & 0.000 & & 0.056 & 0.386 & $(-)$ & 0.063 & & & \\
\hline AREA & 0.073 & & 0.034 & 0.975 & $(-)$ & 0.831 & & & \\
\hline MINDIST & 0.030 & & 0.032 & 0.012 & & 0.623 & & & \\
\hline POP100CR & 0.051 & & 0.027 & 0.400 & $(-)$ & 0.056 & & & \\
\hline RESPOINT & & & 0.037 & 0.005 & & 0.025 & & & \\
\hline TOPEN & 0.850 & $(+)$ & 0.927 & & & & 0.045 & & 0.309 \\
\hline CTRADE & 0.099 & & 0.049 & & & & 0.215 & $(+)$ & 0.050 \\
\hline EXPMANU & 0.000 & & 0.030 & & & & 0.000 & & 0.025 \\
\hline EXPPRIM & 0.409 & $(-)$ & 0.175 & & & & 0.999 & $(-)$ & 0.964 \\
\hline SDGR & 0.000 & & 0.031 & & & & 0.000 & & 0.069 \\
\hline SDBMP & 0.252 & $(-)$ & 0.192 & & & & 0.000 & & 0.126 \\
\hline SDPI & 0.076 & & 0.030 & & & & 0.064 & & 0.053 \\
\hline SDTP & 0.000 & & 0.023 & & & & 0.398 & $(+)$ & 0.228 \\
\hline SDTT & 0.329 & $(-)$ & 0.201 & & & & 0.045 & & 0.026 \\
\hline CIVLEG & & & & 0.589 & $(-)$ & 0.740 & 0.461 & $(-)$ & 0.867 \\
\hline COMLEG & & & & 0.361 & $(-)$ & 0.358 & 0.128 & & 0.467 \\
\hline POLITY2 & & & & 0.291 & $(+)$ & 0.051 & 0.258 & $(+)$ & 0.050 \\
\hline DURABLE & & & & 0.300 & $(+)$ & 0.058 & 0.022 & & 0.031 \\
\hline FREE & & & & 0.020 & & 0.069 & 0.006 & & 0.084 \\
\hline KKZ & & & & 0.988 & $(+)$ & 1.000 & 1.000 & $(+)$ & 0.999 \\
\hline PCI & & & & 0.963 & $(-)$ & 0.996 & 0.924 & $(-)$ & 0.953 \\
\hline EURO1900 & & & & & & & & & \\
\hline MEDSHARE & & & & & & & & & \\
\hline $\begin{array}{l}\text { SRIGHT } \\
\text { CRIGHT }\end{array}$ & & & & & & & & & \\
\hline
\end{tabular}

Note: The dependent variable FD is the aggregate index of overall financial development over period, 1990-99. The variable description is in Appendix Table 1. The Bayesian Model Averaging (BMA) yields the posterior probabilities of inclusion (either "PIPs" or "MC3"), the total posterior model probabilities for all models including a given variable, and the sign certainty index of a relationship ("Sign"). A sign is given to the PIPs greater than 0.2. No sign givern means the sign of estimated relationship being uncertain. Any MC3 greater than 0.2 is in bold. The PIPs is due to Raftery (1995) while the MC3 is due to Hoeting et al. (1994) which also identify the outliers. 
Table 2. Determinants of FD

\begin{tabular}{|c|c|c|c|c|c|c|c|c|c|c|c|c|}
\hline \multirow{3}{*}{$\begin{array}{l}\text { Sample } \\
\text { Method } \\
\text { Variable }\end{array}$} & \multicolumn{4}{|c|}{ Whole Sample } & \multicolumn{4}{|c|}{ Developing Country Sample } & \multicolumn{4}{|c|}{ La Porta Sample } \\
\hline & \multicolumn{2}{|c|}{$\overline{\mathrm{BMA}}$} & \multicolumn{2}{|c|}{ PcGets } & \multicolumn{2}{|c|}{ BMA } & \multicolumn{2}{|c|}{ PcGets } & \multicolumn{2}{|c|}{ BMA } & \multicolumn{2}{|c|}{ PcGets } \\
\hline & PIPs & Sign & Coeff & $t$-value & PIPs & Sign & Coeff & $\mathrm{t}$-value & PIPs & Sign & Coeff & t-value \\
\hline CONSTANT & 1.000 & $(-)$ & -10.563 & -4.074 & 1.000 & $(-)$ & -15.723 & -5.932 & 1.000 & $(+)$ & & \\
\hline GDP90 & 0.946 & $(+)$ & 1.391 & 4.403 & 1.000 & $(+)$ & 2.049 & 7.192 & 0.012 & & & \\
\hline POP90 & 0.996 & $(+)$ & 0.705 & 5.856 & 0.994 & $(+)$ & 0.248 & 2.855 & 1.000 & $(+)$ & 1.314 & 8.610 \\
\hline ETHPOL & 0.999 & $(+)$ & & & 0.007 & & & & 0.039 & & 3.131 & 4.652 \\
\hline ETHNIC & 0.000 & & & & 0.027 & & & & 0.942 & $(+)$ & & \\
\hline RELIGION & 0.004 & & & & 0.492 & $(-)$ & & & 0.067 & & & \\
\hline LANGUAGE & 0.009 & & & & 0.998 & $(+)$ & 1.487 & 2.941 & 0.054 & & & \\
\hline EURFRAC & 0.998 & $(-)$ & -1.287 & -3.694 & 0.002 & & & & 0.978 & $(-)$ & -3.988 & -6.216 \\
\hline REGEAP & 0.999 & $(+)$ & & & 0.001 & & & & 0.093 & & -4.224 & -3.847 \\
\hline REGMENA & 0.001 & & & & 0.998 & $(-)$ & 3.353 & 7.548 & 0.868 & $(+)$ & & \\
\hline REGSA & 0.027 & & & & 0.062 & & & & 0.189 & & -3.000 & -4.524 \\
\hline REGSSA & 0.029 & & & & 0.465 & $(-)$ & & & 0.053 & & & \\
\hline REGLAC & 0.019 & & & & 0.008 & & & & 0.069 & & 2.435 & 3.317 \\
\hline REGWENA & 0.002 & & & & & & & & 0.965 & $(-)$ & -7.789 & -5.614 \\
\hline LANDLOCK & 0.009 & & & & 0.005 & & & & 0.993 & $(+)$ & 2.562 & 3.979 \\
\hline LATITUDE & 0.011 & & -0.041 & -2.948 & 0.322 & $(-)$ & & & 0.051 & & & \\
\hline AREA & 0.992 & $(-)$ & -0.417 & -4.188 & 0.817 & $(-)$ & & & 1.000 & $(-)$ & -0.416 & -4.095 \\
\hline MINDIST & 0.003 & & & & 0.046 & & & & 0.241 & $(-)$ & & \\
\hline POP100CR & 0.000 & & & & 0.377 & $(+)$ & & & 0.043 & & 0.015 & 2.592 \\
\hline RESPOINT & 0.023 & & & & 1.000 & $(-)$ & 3.353 & 7.548 & 0.434 & $(-)$ & -2.960 & -4.633 \\
\hline TOPEN & 0.001 & & & & 1.000 & $(+)$ & 1.990 & 5.192 & 0.985 & $(+)$ & 1.854 & 3.512 \\
\hline CTRADE & 0.492 & $(+)$ & & & 0.903 & $(+)$ & & & 0.050 & & 0.034 & 2.421 \\
\hline EXPMANU & 0.000 & & & & 0.064 & & & & & & 1.246 & 4.264 \\
\hline EXPPRIM & 0.996 & $(-)$ & & & 0.002 & & & & 0.077 & & 1.416 & 2.597 \\
\hline SDGR & 0.000 & & & & 0.005 & & & & 0.980 & $(-)$ & -0.571 & -3.875 \\
\hline SDBMP & 0.346 & $(-)$ & & & 0.658 & $(-)$ & & & 0.120 & & 0.004 & 4.876 \\
\hline SDPI & 0.700 & $(+)$ & & & 1.000 & $(+)$ & 0.001 & 2.193 & 0.504 & $(-)$ & -0.035 & -5.076 \\
\hline SDTP & 0.033 & & & & 0.445 & $(-)$ & & & 0.177 & & -1.390 & -2.263 \\
\hline SDTT & 0.130 & & -0.024 & -3.270 & 0.000 & & & & 0.037 & & 0.036 & 3.222 \\
\hline CIVLEG & 0.529 & $(-)$ & -0.927 & -3.396 & 1.000 & $(-)$ & -4.562 & -5.239 & 0.074 & & & \\
\hline COMLEG & 0.205 & $(+)$ & & & 1.000 & $(+)$ & -3.445 & -3.879 & 0.074 & & 1.687 & 4.452 \\
\hline POLITY2 & 0.058 & & & & 0.992 & $(-)$ & 0.164 & 4.382 & 0.059 & & & \\
\hline DURABLE & 0.764 & $(+)$ & & & 0.000 & & & & 0.686 & $(+)$ & & \\
\hline FREE & 0.002 & & & & 0.035 & & & & 0.035 & & -0.453 & -3.033 \\
\hline KKZ & 1.000 & $(+)$ & 1.846 & 5.064 & 0.370 & $(+)$ & & & 0.992 & $(+)$ & 4.849 & 9.156 \\
\hline PCI & 0.995 & $(-)$ & -5.363 & -5.184 & 1.000 & $(-)$ & -5.391 & -4.026 & 0.995 & $(-)$ & -13.547 & -7.002 \\
\hline EURO1900 & & & & & 0.002 & & & & & & & \\
\hline MEDSHARE & & & & & & & & & 0.405 & $(-)$ & & \\
\hline SRIGHT & & & & & & & & & 0.753 & $(+)$ & & \\
\hline CRIGHT & & & & & & & & & 0.066 & & -0.374 & -3.169 \\
\hline RSS & & & & 51.11 & & & & 17.06 & & & & 3.78 \\
\hline sigma & & & & 0.97 & & & & 0.73 & & & & 0.50 \\
\hline $\mathrm{R}^{\wedge} 2$ & & & & 0.80 & & & & 0.86 & & & & 0.98 \\
\hline $\operatorname{Radj}^{\wedge} 2$ & & & & 0.77 & & & & 0.82 & & & & 0.94 \\
\hline LogLik & & & & 7.20 & & & & 20.84 & & & & 47.21 \\
\hline AIC & & & & 0.09 & & & & -0.40 & & & & -1.11 \\
\hline $\mathrm{HQ}$ & & & & 0.22 & & & & -0.22 & & & & -0.73 \\
\hline SC & & & & 0.42 & & & & 0.08 & & & & -0.05 \\
\hline Chow te & & & & & & & & & & & & \\
\hline Chow test 2 & & & 0.66 & 0.68 & & & 1.35 & 0.28 & & & & \\
\hline $\begin{array}{l}\text { Normality test } \\
\text { Hetero test }\end{array}$ & & & 8.46 & 0.01 & & & 1.76 & 0.41 & & & 1.35 & 0.51 \\
\hline
\end{tabular}

Note: The dependent variable FD is the aggregate index of overall financial development over period, 1990-99. The variable description is in Appendix Table 1. There are 64 observations in the whole sample, 44 observations in the developing country sample and 40 observations in the La Porta sample. The BMA analysis yields the posterior probabilities of inclusion (PIPs) and the sign certainty index of a relationship (Sign). No sign given means the sign of estimated relationship being uncertain.each variable. The PcGets analysis yield coefficient and $\mathrm{t}$-value for the variables in the final model. See p31 for the description of PcGets output. 
Table 3. Top 10 Models and Their Posterior Probabilities for FD

\begin{tabular}{|c|c|c|c|c|c|c|c|c|c|c|}
\hline & 1 & 2 & 3 & 4 & 5 & 6 & 7 & 8 & 9 & 10 \\
\hline GDP90 & $*$ & * & * & * & * & * & * & * & * & * \\
\hline POP90 & $*$ & * & $*$ & $*$ & * & $*$ & * & * & $*$ & * \\
\hline ETHPOL & * & $*$ & * & $*$ & $*$ & $*$ & * & $*$ & * & * \\
\hline EURFRAC & * & * & * & $*$ & * & $*$ & * & * & * & * \\
\hline REGEAP & $*$ & $*$ & * & $*$ & $*$ & $*$ & * & * & * & * \\
\hline AREA & $*$ & $*$ & * & * & $*$ & $*$ & $*$ & * & * & * \\
\hline CTRADE & & & * & * & $*$ & & * & * & & \\
\hline EXPPRIM & $*$ & * & $*$ & $*$ & $*$ & $*$ & * & * & $*$ & * \\
\hline SDBMP & & & * & * & * & & * & & * & \\
\hline SDPI & * & * & * & * & * & & * & * & * & * \\
\hline \multicolumn{11}{|l|}{ SDTT } \\
\hline CIVLEG & * & * & * & * & & * & & & * & \\
\hline COMLEG & & & & & * & & & * & & * \\
\hline DURABLE & $*$ & & $*$ & $*$ & $*$ & & * & * & * & * \\
\hline KKZ & $*$ & $*$ & $*$ & $*$ & $*$ & $*$ & * & * & $*$ & * \\
\hline PCI & * & $*$ & $*$ & * & $*$ & $*$ & * & * & $*$ & * \\
\hline PMP & 0.048 & 0.042 & 0.042 & 0.037 & 0.030 & 0.028 & 0.028 & 0.028 & 0.028 & 0.025 \\
\hline
\end{tabular}

Note: This table presents the top ten models for FD, ranked by their posterior model probability (PMP) in the whole sample. The variable description is in Appendix Table 1. 
Table 4. Geography, policy, institutions and FD

\begin{tabular}{|c|c|c|c|c|}
\hline & $\overline{(1)}$ & $\overline{~(2)}$ & (3) & (4) \\
\hline CONSTANT & $\begin{array}{l}-15.159 \\
{[5.87]^{* *}}\end{array}$ & $\begin{array}{l}-8.220 \\
{[2.95]^{* *}}\end{array}$ & $\begin{array}{l}-10.874 \\
{[3.33]^{* *}}\end{array}$ & $\begin{array}{l}-8.056 \\
{[3.16]^{* *}}\end{array}$ \\
\hline GDP90 & $\begin{array}{l}1.312 \\
{[6.25]^{* *}}\end{array}$ & $\begin{array}{l}0.990 \\
{[2.65]^{*}}\end{array}$ & $\begin{array}{l}1.000 \\
{[2.93]^{* *}}\end{array}$ & $\begin{array}{l}0.958 \\
{[3.01]^{* *}}\end{array}$ \\
\hline POP90 & $\begin{array}{l}0.521 \\
{[3.66]^{* *}}\end{array}$ & $\begin{array}{l}0.584 \\
{[4.75]^{* *}}\end{array}$ & $\begin{array}{l}0.371 \\
{[3.12]^{* *}}\end{array}$ & $\begin{array}{l}0.512 \\
{[4.72]^{* *}}\end{array}$ \\
\hline ETHPOL & $\begin{array}{l}1.117 \\
{[1.88]}\end{array}$ & $\begin{array}{l}1.584 \\
{[2.89]^{* *}}\end{array}$ & $\begin{array}{l}1.029 \\
{[1.65]}\end{array}$ & $\begin{array}{l}1.496 \\
{[3.17]^{* *}}\end{array}$ \\
\hline EURFRAC & $\begin{array}{l}-0.801 \\
{[2.32]^{*}}\end{array}$ & $\begin{array}{l}-1.138 \\
{[3.84]^{* *}}\end{array}$ & $\begin{array}{l}-1.143 \\
{[3.68]^{* *}}\end{array}$ & $\begin{array}{l}-1.100 \\
{[4.16]^{* *}}\end{array}$ \\
\hline REGEAP & $\begin{array}{l}1.961 \\
{[4.61]^{* *}}\end{array}$ & $\begin{array}{l}1.277 \\
{[3.29]^{* *}}\end{array}$ & & $\begin{array}{l}1.239 \\
{[3.92]^{* *}}\end{array}$ \\
\hline AREA & $\begin{array}{l}-0.177 \\
{[1.58]}\end{array}$ & $\begin{array}{l}-0.457 \\
{[4.72]^{* *}}\end{array}$ & & $\begin{array}{l}-0.412 \\
{[4.41]^{* *}}\end{array}$ \\
\hline CTRADE & $\begin{array}{l}0.044 \\
{[4.07]^{* *}}\end{array}$ & & $\begin{array}{l}0.025 \\
{[2.01]}\end{array}$ & \\
\hline EXPPRIM & $\begin{array}{l}-0.609 \\
{[1.54]}\end{array}$ & & $\begin{array}{l}-0.970 \\
{[3.11]^{* *}}\end{array}$ & $\begin{array}{l}-0.943 \\
{[4.06]^{* *}}\end{array}$ \\
\hline SDBMP & $\begin{array}{l}-0.001 \\
{[3.79]^{* *}}\end{array}$ & & $\begin{array}{l}0.000 \\
{[0.22]}\end{array}$ & \\
\hline SDPI & $\begin{array}{l}0.001 \\
{[4.12]^{* *}}\end{array}$ & & $\begin{array}{l}0.001 \\
{[3.51]^{* *}}\end{array}$ & $\begin{array}{l}0.001 \\
{[4.50]^{* *}}\end{array}$ \\
\hline SDTT & $\begin{array}{l}-0.010 \\
{[1.20]}\end{array}$ & & $\begin{array}{l}-0.010 \\
{[0.93]}\end{array}$ & \\
\hline CIVLEG & & $\begin{array}{l}-1.159 \\
{[2.22]^{*}}\end{array}$ & $\begin{array}{l}-1.712 \\
{[3.33]^{* *}}\end{array}$ & $\begin{array}{l}-0.600 \\
{[2.49]^{*}}\end{array}$ \\
\hline COMLEG & & $\begin{array}{l}-0.656 \\
{[1.28]}\end{array}$ & $\begin{array}{l}-0.998 \\
{[1.96]}\end{array}$ & \\
\hline DURABLE & & $\begin{array}{l}0.018 \\
{[1.66]}\end{array}$ & $\begin{array}{l}0.011 \\
{[0.73]}\end{array}$ & $\begin{array}{l}0.017 \\
{[1.54]}\end{array}$ \\
\hline KKZ & & $\begin{array}{l}1.489 \\
{[4.40]^{* *}}\end{array}$ & $\begin{array}{l}1.237 \\
{[3.30]^{* *}}\end{array}$ & $\begin{array}{l}1.445 \\
{[5.12]^{* *}}\end{array}$ \\
\hline PCI & & $\begin{array}{l}-4.006 \\
{[4.29]^{* *}}\end{array}$ & $\begin{array}{l}-3.791 \\
{[3.98]^{* *}}\end{array}$ & $\begin{array}{l}-4.258 \\
{[4.90]^{* *}}\end{array}$ \\
\hline \multicolumn{5}{|c|}{ Standardised coefficients } \\
\hline ETHPOL & 0.49 & 0.72 & 0.45 & 0.68 \\
\hline EURFRAC & -0.46 & -0.62 & -0.63 & -0.61 \\
\hline AREA & -0.15 & -0.29 & & -0.26 \\
\hline CTRADE & -0.04 & & -0.05 & \\
\hline SDBMP & -0.06 & & -0.06 & \\
\hline SDPI & -0.06 & & -0.06 & -0.06 \\
\hline SDTT & -0.07 & & -0.07 & \\
\hline DURABLE & & -0.05 & -0.06 & -0.05 \\
\hline KKZ & & 0.68 & 0.55 & 0.66 \\
\hline PCI & & -2.05 & -1.94 & -2.17 \\
\hline $\begin{array}{l}\text { Observations } \\
\text { R-square }\end{array}$ & $\begin{array}{l}64 \\
0.740\end{array}$ & $\begin{array}{l}64 \\
0.820\end{array}$ & $\begin{array}{l}64 \\
0.790\end{array}$ & $\begin{array}{l}64 \\
0.860\end{array}$ \\
\hline
\end{tabular}

Note: The models are estimated by OLS. The dependent variable is FD, over 1990-99. The t-values are reported in brackets. Variable descriptions are from Appendix Table 1. The standardised coefficients show the change of a standard deviation of FD due to a one standard deviation change in a variable for those other than initial GDP and population, binary variables. 
Table 5. Determinants of FDBANK

\begin{tabular}{|c|c|c|c|c|c|c|c|c|c|c|c|c|}
\hline \multirow{3}{*}{$\begin{array}{l}\text { Sample } \\
\text { Method } \\
\text { Variable }\end{array}$} & \multicolumn{4}{|c|}{ Whole Sample } & \multicolumn{4}{|c|}{ Developing Country Sample } & \multicolumn{4}{|c|}{ La Porta Sample } \\
\hline & \multicolumn{2}{|c|}{$\overline{\mathrm{BMA}}$} & \multicolumn{2}{|c|}{ PcGets } & \multicolumn{2}{|c|}{ BMA } & \multicolumn{2}{|c|}{ PcGets } & \multicolumn{2}{|c|}{$\overline{\mathrm{BMA}}$} & \multicolumn{2}{|c|}{ PcGets } \\
\hline & PIPs & Sign & Coeff & t-value & PIPs & Sign & Coeff & t-value & PIPs & Sign & Coeff & t-value \\
\hline CONSTANT & 1.000 & $(-)$ & -2.523 & -1.579 & 1.000 & $(-)$ & -4.218 & -2.614 & 1.000 & $(+)$ & & \\
\hline GDP90 & 0.832 & $(+)$ & 0.449 & 2.445 & 0.413 & $(+)$ & 0.568 & 2.598 & 0.175 & & & \\
\hline POP90 & 0.017 & & & & 0.000 & & & & 0.858 & $(+)$ & & \\
\hline ETHPOL & 0.012 & & & & 0.008 & & & & 0.692 & $(-)$ & & \\
\hline ETHNIC & 0.001 & & & & 0.000 & & & & 0.852 & $(+)$ & & \\
\hline RELIGION & & & & & 0.004 & & & & 0.203 & $(-)$ & & \\
\hline LANGUAGE & 0.000 & & & & 0.000 & & & & 0.060 & & & \\
\hline EURFRAC & 0.000 & & & & 0.000 & & & & 0.326 & $(-)$ & -0.967 & -2.751 \\
\hline REGEAP & 1.000 & $(+)$ & 1.979 & 6.770 & 0.929 & $(+)$ & 1.879 & 5.125 & 0.268 & $(+)$ & & \\
\hline REGMENA & 1.000 & $(+)$ & 1.327 & 4.115 & 0.928 & $(+)$ & 2.025 & 4.534 & 1.000 & $(+)$ & & \\
\hline REGSA & 1.000 & $(+)$ & 2.123 & 5.019 & 0.926 & $(+)$ & & & 0.344 & $(+)$ & & \\
\hline REGSSA & 0.001 & & & & 0.072 & & & & 0.336 & $(+)$ & & \\
\hline REGLAC & 0.000 & & & & 0.072 & & & & 0.144 & & & \\
\hline REGWENA & 0.001 & & & & & & & & 0.767 & $(-)$ & -1.750 & -3.295 \\
\hline LANDLOCK & 0.008 & & -0.224 & -0.817 & 0.259 & $(-)$ & & & 0.734 & $(+)$ & & \\
\hline LATITUDE & 0.000 & & & & 0.000 & & & & 0.048 & & & \\
\hline AREA & 0.000 & & & & 0.000 & & & & 1.000 & $(-)$ & & \\
\hline MINDIST & 0.804 & $(-)$ & -0.205 & -2.630 & 0.000 & & & & 0.343 & $(-)$ & -0.078 & -2.270 \\
\hline POP100CR & 0.001 & & & & 0.000 & & & & 0.257 & $(-)$ & & \\
\hline RESPOINT & 0.361 & $(-)$ & & & 0.321 & $(-)$ & -0.680 & -2.674 & 0.770 & $(-)$ & & \\
\hline TOPEN & 0.703 & $(+)$ & 0.790 & 2.118 & 0.682 & $(+)$ & & & 0.969 & $(+)$ & 1.942 & 4.213 \\
\hline CTRADE & 0.862 & $(+)$ & 0.020 & 2.730 & 0.158 & & & & 0.949 & $(-)$ & & \\
\hline EXPMANU & 0.095 & & & & 0.184 & & & & & & & \\
\hline EXPPRIM & 0.126 & & & & 0.134 & & & & 0.083 & & & \\
\hline SDGR & 0.000 & & & & 0.000 & & & & 0.940 & $(-)$ & & \\
\hline SDBMP & 0.005 & & & & 0.035 & & & & 0.175 & & & \\
\hline SDPI & 0.001 & & 0.000 & 0.383 & 0.035 & & & & 0.165 & & & \\
\hline SDTP & 0.000 & & & & 0.000 & & & & 0.129 & & & \\
\hline SDTT & 0.109 & & & & 0.143 & & & & 0.062 & & & \\
\hline CIVLEG & 0.043 & & & & 0.013 & & & & 0.116 & & & \\
\hline COMLEG & 0.182 & & -0.367 & -1.743 & 0.035 & & & & 0.107 & & 0.691 & 2.305 \\
\hline POLITY2 & 0.335 & $(+)$ & 0.060 & 2.079 & 0.059 & & 0.113 & 2.709 & 0.037 & & & \\
\hline DURABLE & 0.000 & & & & 0.000 & & & & 0.028 & & & \\
\hline FREE & 0.031 & & & & 0.033 & & & & 0.024 & & & \\
\hline KKZ & 1.000 & $(+)$ & 0.733 & 3.628 & 1.000 & $(+)$ & 0.753 & 2.737 & 1.000 & $(+)$ & 1.349 & 4.850 \\
\hline PCI & 0.828 & $(-)$ & -3.433 & -3.622 & 0.430 & $(-)$ & -4.340 & -2.944 & 0.832 & $(-)$ & & \\
\hline EURO1900 & & & & & 0.045 & & & & & & & \\
\hline MEDSHARE & & & & & & & & & 0.130 & & & \\
\hline SRIGHT & & & & & & & & & 0.662 & $(+)$ & & \\
\hline CRIGHT & & & & & & & & & 0.729 & $(-)$ & & \\
\hline RSS & & & & 51.30 & & & & 51.41 & & & & 29.21 \\
\hline sigma & & & & 0.82 & & & & 0.94 & & & & 0.93 \\
\hline $\mathrm{R}^{\wedge} 2$ & & & & 0.82 & & & & 0.65 & & & & 0.76 \\
\hline $\operatorname{Radj}^{\wedge} 2$ & & & & 0.79 & & & & 0.61 & & & & 0.72 \\
\hline LogLik & & & & 26.08 & & & & 8.82 & & & & 6.29 \\
\hline AIC & & & & -0.27 & & & & -0.02 & & & & -0.01 \\
\hline HQ & & & & -0.11 & & & & 0.08 & & & & 0.08 \\
\hline SC & & & & 0.12 & & & & 0.23 & & & & 0.24 \\
\hline Chow test 1 & & & 1.63 & 0.07 & & & & & & & & \\
\hline Chow test 2 & & & 2.94 & 0.01 & & & 2.27 & 0.05 & & & & \\
\hline Normality test & & & 0.65 & 0.72 & & & 1.45 & 0.48 & & & 0.93 & 0.63 \\
\hline Hetero test & & & 20.25 & 0.51 & & & & & & & & \\
\hline
\end{tabular}

Note: The dependent variable FDBANK is the index of financial interdediary development over period, 1990-99. Variable description is in Appendix Table 1. There are 91 observations in the whole sample, 70 observations in the developing country sample and 40 observations in the La Porta sample. The BMA analysis yields the posterior probabilities of inclusion (PIPs) and the sign certainty index of a relationship (Sign). No sign given means the sign of estimated relationship being uncertain.each variable. The PcGets analysis yields coefficient and $t$-value for the variables in the final model. See p31 for the description of PcGets output. 
Table 6. Determinants of FDSTOCK

\begin{tabular}{|c|c|c|c|c|c|c|c|c|c|c|c|c|}
\hline \multirow{3}{*}{$\begin{array}{l}\text { Sample } \\
\text { Method } \\
\text { Variable }\end{array}$} & \multicolumn{4}{|c|}{ Whole Sample } & \multicolumn{4}{|c|}{ Developing Country Sample } & \multicolumn{4}{|c|}{ La Porta Sample } \\
\hline & \multicolumn{2}{|c|}{ BMA } & \multicolumn{2}{|c|}{ PcGets } & \multicolumn{2}{|c|}{ BMA } & \multicolumn{2}{|c|}{ PcGets } & \multicolumn{2}{|c|}{$\overline{\mathrm{BMA}}$} & \multicolumn{2}{|c|}{$\overline{\text { PcGets }}$} \\
\hline & PIPs & Sign & Coeff & t-value & PIPs & Sign & Coeff & t-value & PIPs & Sign & Coeff & t-value \\
\hline CONSTANT & 1.000 & $(-)$ & & & 1.000 & $(-)$ & -8.131 & -6.444 & 1.000 & $(-)$ & & \\
\hline GDP90 & 0.183 & & & & 1.000 & $(+)$ & 0.645 & 4.911 & 0.045 & & -0.669 & -3.836 \\
\hline POP90 & 1.000 & $(+)$ & 0.435 & 8.414 & 1.000 & $(+)$ & 0.290 & 7.118 & 0.919 & $(+)$ & 0.732 & 4.701 \\
\hline ETHPOL & 0.985 & $(+)$ & 0.791 & 3.379 & 0.000 & & & & 0.832 & $(+)$ & 1.490 & 2.897 \\
\hline ETHNIC & 0.000 & & & & 0.014 & & & & 0.009 & & & \\
\hline RELIGION & 0.008 & & & & 0.974 & $(+)$ & 0.989 & 3.567 & 0.232 & $(+)$ & & \\
\hline LANGUAGE & 0.039 & & & & 0.005 & & & & 0.046 & & & \\
\hline EURFRAC & 0.210 & $(-)$ & -0.611 & -3.016 & 0.977 & $(-)$ & & & 0.783 & $(-)$ & -0.932 & -2.783 \\
\hline REGEAP & 0.937 & $(+)$ & -1.301 & -3.001 & 0.056 & & & & 0.016 & & -0.833 & -1.689 \\
\hline REGMENA & 0.062 & & -1.653 & -4.024 & 0.021 & & -1.714 & -2.791 & 0.008 & & & \\
\hline REGSA & 0.035 & & -2.485 & -5.434 & 0.351 & $(-)$ & -1.623 & -2.807 & 0.721 & $(-)$ & -2.367 & -3.686 \\
\hline REGSSA & 0.022 & & -1.427 & -3.245 & 0.892 & $(-)$ & -2.098 & -3.419 & 0.034 & & & \\
\hline REGLAC & 0.000 & & -1.128 & -2.828 & 0.012 & & -1.562 & -3.196 & 0.000 & & & \\
\hline REGWENA & 0.063 & & -1.716 & -3.664 & & & & & 0.033 & & -1.258 & -2.367 \\
\hline LANDLOCK & 0.000 & & & & 0.007 & & & & 0.004 & & & \\
\hline LATITUDE & 0.000 & & & & 0.000 & & & & 0.040 & & & \\
\hline AREA & 0.985 & $(-)$ & -0.245 & -6.484 & 0.000 & & & & 0.935 & $(-)$ & -0.462 & -4.611 \\
\hline MINDIST & 0.120 & & & & 0.000 & & & & 0.722 & $(+)$ & 0.173 & 2.361 \\
\hline POP100CR & 0.037 & & & & 0.006 & & & & 0.000 & & & \\
\hline RESPOINT & 0.007 & & & & 0.532 & $(-)$ & & & 0.000 & & & \\
\hline TOPEN & 0.191 & & 0.578 & 2.686 & 1.000 & $(+)$ & 0.901 & 4.497 & 0.098 & & 0.647 & 1.361 \\
\hline CTRADE & 0.000 & & & & 0.000 & & & & 0.081 & & & \\
\hline EXPMANU & 0.901 & $(+)$ & & & 0.003 & & & & 0.165 & & 0.602 & 1.976 \\
\hline EXPPRIM & 0.003 & & & & 0.000 & & & & 0.065 & & 0.858 & 1.948 \\
\hline SDGR & 0.141 & & -0.129 & -3.320 & 0.244 & $(-)$ & 0.000 & -3.172 & 0.555 & $(-)$ & -0.351 & -3.908 \\
\hline SDBMP & 0.014 & & & & 0.736 & $(-)$ & & & 0.252 & $(-)$ & & \\
\hline SDPI & 0.000 & & & & 0.068 & & & & 0.076 & & & \\
\hline SDTP & 0.745 & $(+)$ & & & 0.001 & & & & 1.000 & $(+)$ & 1.847 & 3.524 \\
\hline SDTT & 0.000 & & & & 0.000 & & & & 0.000 & & & \\
\hline CIVLEG & 0.002 & & & & 0.615 & $(-)$ & & & 0.006 & & & \\
\hline COMLEG & 0.111 & & 0.582 & 4.032 & 0.133 & & 0.321 & 2.212 & 0.005 & & & \\
\hline POLITY2 & 0.010 & & & & 0.045 & & & & 0.036 & & & \\
\hline DURABLE & 0.216 & $(+)$ & 0.013 & 3.003 & 0.040 & & & & 0.688 & $(+)$ & 0.022 & 2.619 \\
\hline FREE & 0.134 & & & & 0.164 & & 0.161 & 2.983 & 0.051 & & & \\
\hline KKZ & 0.976 & $(+)$ & 0.701 & 4.687 & 0.463 & $(+)$ & & & 0.894 & $(+)$ & 1.503 & 4.310 \\
\hline PCI & 0.245 & $(-)$ & -1.828 & -4.349 & 0.000 & & & & 0.006 & & & \\
\hline EURO1900 & & & & & 0.006 & & -0.813 & -1.681 & & & & \\
\hline MEDSHARE & & & & & & & & & 0.249 & $(-)$ & & \\
\hline SRIGHT & & & & & & & & & 0.108 & & & \\
\hline CRIGHT & & & & & & & & & 0.002 & & & \\
\hline RSS & & & & 14.02 & & & & 4.27 & & & & 17.87 \\
\hline sigma & & & & 0.47 & & & & 0.34 & & & & 0.74 \\
\hline $\mathrm{R}^{\wedge} 2$ & & & & 0.87 & & & & 0.84 & & & & 0.78 \\
\hline $\operatorname{Radj}^{\wedge} 2$ & & & & 0.84 & & & & 0.78 & & & & 0.68 \\
\hline LogLik & & & & 71.04 & & & & 61.53 & & & & 24.71 \\
\hline AIC & & & & -1.33 & & & & -1.90 & & & & -0.36 \\
\hline HQ & & & & -1.13 & & & & -1.70 & & & & -0.12 \\
\hline SC & & & & -0.83 & & & & -1.37 & & & & 0.26 \\
\hline Chow test 1 & & & 1.20 & 0.33 & & & & & & & & \\
\hline Chow test 2 & & & 0.88 & 0.54 & & & 1.47 & 0.23 & & & 0.15 & 0.96 \\
\hline Normality test & & & & & & & 9.04 & 0.01 & & & 8.52 & 0.01 \\
\hline Hetero test & & & 31.22 & 0.22 & & & & & & & & \\
\hline
\end{tabular}

Note: The dependent variable FDSTOCK is the index of stock market development over period, 1990-99. The variable description is in Appendix Table 1 . There are 81 observations in the whole sample, 50 observations in the developing country sample and 49 observations in the La Porta sample. The BMA analysis yields the posterior probabilities of inclusion (PIPs) and the sign certainty index of a relationship (Sign). No sign given means the sign relationship being uncertain.each variable. The PcGets analysis yields coefficient and $\mathrm{t}$-value for the variables in the final model. See p31 for description of PcGets output. 
Table 7. Determinants of FDEFF

\begin{tabular}{|c|c|c|c|c|c|c|c|c|c|c|c|c|}
\hline \multirow{3}{*}{$\begin{array}{l}\text { Sample } \\
\text { Method } \\
\text { Variable }\end{array}$} & \multicolumn{4}{|c|}{ Whole Sample } & \multicolumn{4}{|c|}{ Developing Country Sample } & \multicolumn{4}{|c|}{ La Porta Sample } \\
\hline & \multicolumn{2}{|c|}{$\overline{\mathrm{BMA}}$} & \multicolumn{2}{|c|}{ PcGets } & \multicolumn{2}{|c|}{ BMA } & \multicolumn{2}{|c|}{ PcGets } & \multicolumn{2}{|c|}{$\overline{\mathrm{BMA}}$} & \multicolumn{2}{|c|}{ PcGets } \\
\hline & PIPs & Sign & Coeff & t-value & PIPs & Sign & Coeff & t-value & PIPs & Sign & Coeff & t-value \\
\hline CONSTANT & 1.000 & $(+)$ & & & 1.000 & $(+)$ & 9.145 & 4.200 & 1.000 & $(+)$ & & \\
\hline GDP90 & 0.010 & & & & 0.996 & $(-)^{\prime}$ & -1.456 & -6.307 & 0.243 & $(+)$ & 0.661 & 4.845 \\
\hline POP90 & 0.041 & & & & 0.856 & $(-)$ & -0.536 & -5.097 & 0.672 & $(-)$ & -0.411 & -3.726 \\
\hline ETHPOL & 0.000 & & & & 0.987 & $(+)$ & & & 0.034 & & & \\
\hline ETHNIC & 0.000 & & & & 0.027 & & & & 0.004 & & & \\
\hline RELIGION & 0.375 & $(-)$ & -0.789 & -1.839 & 0.061 & & & & 0.479 & $(-)$ & & \\
\hline LANGUAGE & 0.000 & & & & 0.996 & $(-)$ & -0.975 & $-2.27 y$ & 0.170 & & & \\
\hline EURFRAC & 0.028 & & & & 0.336 & $(-)$ & & & 0.894 & $(+)$ & 1.039 & 3.902 \\
\hline REGEAP & 0.989 & $(-)$ & -1.397 & -5.028 & 0.029 & & & & 0.075 & & & \\
\hline REGMENA & 0.962 & $(-)$ & -1.685 & -5.377 & 1.000 & $(-)$ & -2.613 & -7.077 & 0.716 & $(-)$ & -0.894 & -2.535 \\
\hline REGSA & 0.986 & $(-)$ & -2.326 & -5.240 & 1.000 & $(-)$ & & & 0.707 & $(-)$ & & \\
\hline REGSSA & 0.033 & & & & 0.006 & & & & 0.029 & & & \\
\hline REGLAC & 0.037 & & & & 0.045 & & & & 0.225 & $(+)$ & & \\
\hline REGWENA & 0.777 & $(-)$ & & & & & & & 0.071 & & & \\
\hline LANDLOCK & 0.000 & & & & 0.021 & & & & 0.031 & & & \\
\hline LATITUDE & 0.000 & & & & 0.055 & & & & 0.001 & & & \\
\hline AREA & 0.021 & & & & 0.851 & $(+)$ & 0.411 & 4.515 & 0.289 & $(+)$ & 0.160 & 2.168 \\
\hline MINDIST & 0.066 & & & & 0.024 & & & & 0.015 & & & \\
\hline POP100CR & 0.000 & & & & 0.003 & & & & 0.028 & & & \\
\hline RESPOINT & 0.103 & & 0.667 & 2.473 & 0.996 & $(+)$ & 1.379 & 5.697 & 0.019 & & & \\
\hline TOPEN & 0.052 & & & & 0.996 & $(-)$ & & & 0.030 & & & \\
\hline CTRADE & 0.000 & & & & 0.088 & & & & 0.000 & & & \\
\hline EXPMANU & 0.140 & & & & 0.007 & & & & 0.270 & $(-)$ & & \\
\hline EXPPRIM & 0.926 & $(+)$ & & & 0.000 & & & & 0.001 & & & \\
\hline SDGR & 0.002 & & & & 0.089 & & & & 0.755 & $(+)$ & 0.149 & 2.443 \\
\hline SDBMP & 0.021 & & & & 0.000 & & & & 0.000 & & & \\
\hline SDPI & 0.134 & & 0.000 & -0.999 & 0.996 & $(-)$ & -0.001 & -4.142 & 0.023 & & & \\
\hline SDTP & 0.086 & & -0.332 & -1.144 & 0.082 & & & & 0.932 & $(-)$ & -2.084 & -5.550 \\
\hline SDTT & 0.058 & & & & 0.003 & & & & 0.121 & & & \\
\hline CIVLEG & 0.034 & & 1.773 & 3.340 & 0.996 & $(+)$ & 2.828 & 3.756 & 0.000 & & & \\
\hline COMLEG & 0.102 & & 2.127 & 3.725 & 0.996 & $(+)$ & 2.133 & 2.789 & 0.000 & & & \\
\hline POLITY2 & 0.000 & & & & 0.981 & $(-)$ & -0.144 & -4.539 & 0.000 & & & \\
\hline DURABLE & 0.000 & & & & 0.059 & & & & 0.000 & & & \\
\hline FREE & 0.985 & $(-)$ & & & 0.027 & & & & 0.125 & & & \\
\hline KKZ & 1.000 & $(-)$ & -1.119 & -8.260 & 0.768 & $(-)$ & & & 1.000 & $(-)$ & -2.044 & -8.788 \\
\hline PCI & 0.000 & & & & 0.996 & $(+)$ & 6.226 & 5.693 & 0.703 & $(+)$ & & \\
\hline EURO1900 & & & & & 0.159 & & & & & & & \\
\hline MEDSHARE & & & & & & & & & 0.003 & & & \\
\hline SRIGHT & & & & & & & & & 0.001 & & & \\
\hline CRIGHT & & & & & & & & & 0.000 & & & \\
\hline RSS & & & & 40.53 & & & & 14.68 & & & & 19.89 \\
\hline sigma & & & & 0.77 & & & & 0.64 & & & & 0.70 \\
\hline $\mathrm{R}^{\wedge} 2$ & & & & 0.74 & & & & 0.82 & & & & 0.82 \\
\hline $\operatorname{Radj}^{\wedge} 2$ & & & & 0.70 & & & & 0.76 & & & & 0.79 \\
\hline LogLik & & & & 26.36 & & & & 28.43 & & & & 22.09 \\
\hline AIC & & & & -0.41 & & & & -0.68 & & & & -0.57 \\
\hline $\mathrm{HQ}$ & & & & -0.29 & & & & -0.51 & & & & -0.46 \\
\hline SC & & & & -0.11 & & & & -0.22 & & & & -0.27 \\
\hline Chow test 1 & & & & & & & & & & & & \\
\hline Chow test 2 & & & 2.27 & 0.01 & & & 0.70 & 0.60 & & & 0.45 & 0.77 \\
\hline Normality test & & & 16.62 & 0.34 & & & 0.11 & 0.95 & & & 2.82 & 0.24 \\
\hline Hetero test & & & & & & & & & & & & \\
\hline
\end{tabular}

Note: The dependent variable FDEFF is the index of financial efficiency development over period, 1990-99. The variable description is in Appendix Table 1. There are 79 observations in the whole sample, 48 observations in the developing country sample and 49 observations in the La Porta sample. The BMA analysis yields the posterior probabilities of inclusion (PIPs) and the sign certainty index of a relationship (Sign). No sign given means the sign of estimated relationship being uncertain.each variable. The PcGets analysis yields coefficient and t-value for the variables in the final model. See p31 for the description of PcGets output. 
Table 8. Determinants of FDSIZE

\begin{tabular}{|c|c|c|c|c|c|c|c|c|c|c|c|c|}
\hline \multirow{3}{*}{$\begin{array}{l}\text { Sample } \\
\text { Method } \\
\text { Variable }\end{array}$} & \multicolumn{4}{|c|}{ Whole Sample } & \multicolumn{4}{|c|}{ "Developing Country Sample } & \multicolumn{4}{|c|}{ La Porta Sample } \\
\hline & \multicolumn{2}{|c|}{$\overline{\mathrm{BMA}}$} & \multicolumn{2}{|c|}{ PcGets } & \multicolumn{2}{|c|}{ BMA } & \multicolumn{2}{|c|}{ PcGets } & \multicolumn{2}{|c|}{$\overline{\mathrm{BMA}}$} & \multicolumn{2}{|c|}{ PcGets } \\
\hline & PIPS & Sign & Coeff & t-value & PIPs & Sign & Coeff & t-value & PIPs & Sign & Coeff & t-value \\
\hline$\overline{\text { CONSTANT }}$ & 1.000 & $(-)$ & & & 1.000 & $(-)$ & -11.170 & -4.993 & 1.000 & $(-)$ & & \\
\hline GDP90 & 1.000 & $(+)$ & & & 0.809 & $(+)$ & 0.356 & 2.073 & 0.825 & $(+)$ & & \\
\hline POP90 & 0.999 & $(+)$ & 0.286 & 3.708 & 0.961 & $(+)$ & 0.247 & 4.185 & 0.624 & $(+)$ & & \\
\hline ETHPOL & 0.068 & & & & 0.282 & $(+)$ & & & 0.009 & & & \\
\hline ETHNIC & 0.000 & & & & 0.093 & & 1.558 & 3.456 & 0.138 & & & \\
\hline RELIGION & 0.000 & & & & 0.808 & $(+)$ & & & 0.000 & & & \\
\hline LANGUAGE & 0.342 & $(+)$ & & & 0.392 & $(+)$ & & & 0.346 & $(+)$ & & \\
\hline EURFRAC & 0.049 & & -0.535 & -2.043 & 0.043 & & & & 0.005 & & & \\
\hline REGEAP & 0.351 & $(+)$ & & & 0.000 & & & & 0.505 & $(+)$ & & \\
\hline REGMENA & 0.552 & $(+)$ & & & 1.000 & $(+)$ & & & 0.111 & & & \\
\hline REGSA & 0.016 & & -0.568 & -1.324 & 0.018 & & -1.621 & -4.294 & 0.137 & & & \\
\hline REGSSA & 0.003 & & & & 0.152 & & -0.607 & -2.369 & 0.003 & & & \\
\hline REGLAC & 0.013 & & & & 0.042 & & & & 0.045 & & & \\
\hline REGWENA & 0.554 & $(-)$ & -1.224 & -3.319 & & & & & 0.640 & $(-)$ & -1.209 & -2.479 \\
\hline LANDLOCK & 0.000 & & & & 0.105 & & & & 0.987 & $(+)$ & & \\
\hline LATITUDE & 0.000 & & & & 0.002 & & 0.043 & 4.284 & 0.063 & & & \\
\hline AREA & 0.999 & $(-)$ & -0.267 & -4.605 & 0.002 & & & & 0.379 & $(-)$ & & \\
\hline MINDIST & 0.008 & & & & 0.016 & & 0.511 & 2.483 & 0.594 & $(-)$ & & \\
\hline POP100CR & 0.040 & & & & 0.269 & $(+)$ & 0.012 & 3.817 & 0.080 & & & \\
\hline RESPOINT & 0.001 & & & & 0.039 & & -0.388 & -2.045 & 0.034 & & & \\
\hline TOPEN & 0.987 & $(+)$ & 1.353 & 4.065 & 1.000 & $(+)$ & 1.313 & 4.984 & 0.616 & $(+)$ & 1.971 & 5.253 \\
\hline CTRADE & 0.000 & & & & 0.076 & & & & 0.843 & $(+)$ & & \\
\hline EXPMANU & 0.000 & & & & 0.005 & & & & 0.001 & & & \\
\hline EXPPRIM & 0.003 & & & & 0.034 & & & & 0.020 & & & \\
\hline SDGR & 0.000 & & & & 0.590 & $(-)$ & & & 0.768 & $(-)$ & & \\
\hline SDBMP & 0.218 & $(-)$ & & & 0.491 & $(-)$ & -0.001 & -3.310 & 0.032 & & & \\
\hline SDPI & 0.000 & & & & 0.000 & & & & 0.854 & $(-)$ & -0.008 & -2.716 \\
\hline SDTP & 0.000 & & & & 0.000 & & & & 0.824 & $(-)$ & & \\
\hline SDTT & 0.018 & & & & 0.183 & & & & 0.019 & & & \\
\hline CIVLEG & 0.757 & $(-)$ & & & 0.895 & $(-)$ & -0.752 & -4.225 & 0.010 & & & \\
\hline COMLEG & 0.243 & $(+)$ & & & 0.029 & & & & 0.010 & & & \\
\hline POLITY2 & 0.000 & & & & 0.012 & & & & 0.000 & & & \\
\hline DURABLE & 0.244 & $(+)$ & 0.022 & 3.009 & 0.000 & & & & 0.005 & & & \\
\hline FREE & 0.004 & & & & 0.249 & $(+)$ & & & 0.002 & & & \\
\hline KKZ & 0.155 & & 0.697 & 3.231 & 0.467 & $(+)$ & & & 0.097 & & & \\
\hline $\mathrm{PCI}$ & 0.888 & $(-)$ & -1.348 & -1.921 & 0.008 & & & & 0.879 & $(-)$ & & \\
\hline EURO1900 & & & & & 0.000 & & -2.359 & -4.514 & & & & \\
\hline MEDSHARE & & & & & & & & & 0.015 & & & \\
\hline SRIGHT & & & & & & & & & 1.000 & $(+)$ & & \\
\hline CRIGHT & & & & & & & & & 0.001 & & & \\
\hline RSS & & & & 39.78 & & & & 9.38 & & & & 46.94 \\
\hline sigma & & & & 0.79 & & & & 0.50 & & & & 1.10 \\
\hline $\mathrm{R}^{\wedge} 2$ & & & & 0.65 & & & & 0.75 & & & & 0.42 \\
\hline $\operatorname{Radj}^{\wedge} 2$ & & & & 0.61 & & & & 0.66 & & & & 0.39 \\
\hline LogLik & & & & 22.15 & & & & 43.18 & & & & -2.34 \\
\hline AIC & & & & -0.36 & & & & -1.14 & & & & 0.25 \\
\hline HQ & & & & -0.25 & & & & -0.94 & & & & 0.30 \\
\hline $\mathrm{SC}$ & & & & -0.08 & & & & -0.61 & & & & 0.38 \\
\hline Chow test 1 & & & 0.80 & 0.74 & & & & & & & & \\
\hline Chow test 2 & & & 1.17 & 0.34 & & & 1.11 & 0.37 & & & & \\
\hline $\begin{array}{l}\text { Normality test } \\
\text { Hetero test }\end{array}$ & & & 8.90 & 0.01 & & & 0.29 & 0.87 & & & 8.45 & 0.01 \\
\hline
\end{tabular}

Note: The dependent variable FDSIZE is the index of financial size development over period, 1990-99. The variable description is in Appendix Table 1. There are 73 observations in the whole sample, 51 observations in the developing country sample and 42 observations in the La Porta sample. The BMA analysis yields the posterior probabilities of inclusion (PIPs) and the sign certainty index of a relationship (Sign). No sign given means the sign of estimated relationship being uncertain.each variable. The PcGets analysis yields coefficient and t-value for the variables in the final model. See p31 for the description of PcGets output. 


\section{Appendix Table 1. The variables}

\begin{tabular}{|c|c|c|}
\hline$\overline{\text { VARIABLE }}$ & DESCRIPTION & SOURCE \\
\hline \multicolumn{3}{|c|}{ Dependent variables } \\
\hline FD & $\begin{array}{l}\text { Index for overall financial development. The first principal component of private credit(PRIVO), } \\
\text { liquidity liability (LLY), commercial-central bank (BTOT), overhead cost (OVC), net interest margin } \\
\text { (NIM), stock market capitalisation (MCAP), total value traded (TVT) and turnover ratio (TOR) in 1990s. }\end{array}$ & $\begin{array}{l}\text { World Bank's Financial } \\
\text { Structure and Economic } \\
\text { Development Database } \\
\text { (FSED), } 2005\end{array}$ \\
\hline FDBANK & $\begin{array}{l}\text { Index for financial intermediary development. The first principal component of PRIVO, LLY, BTOT, } \\
\text { OVC and NIM in 1990s. }\end{array}$ & FSED, 2005 \\
\hline FDSTOCK & Index for stock market development. The first principal component of MCAP, TVT and TOR in 1990s. & FSED, 2005 \\
\hline FDEFF & $\begin{array}{l}\text { Index for financial efficiency development. The first principal component of OVC, NIM, TVT and TOR } \\
\text { in 1990s. }\end{array}$ & FSED, 2005 \\
\hline FDSIZE & $\begin{array}{l}\text { Index for financial size development (financial depth). the first principal component of LLY and MCAP } \\
\text { in 1990s. }\end{array}$ & FSED, 2005 \\
\hline FDBOND & $\begin{array}{l}\text { index for bond market developpment, the sum of private bond and public bond share over GDP in } \\
\text { 1990s. }\end{array}$ & FSED, 2005 \\
\hline \multicolumn{3}{|c|}{$\underline{\text { Policy variables }}$} \\
\hline TOPEN & $\begin{array}{l}\text { The proportion of years that a country is open to trade during 1965-90, by the criteria in Sachs and } \\
\text { Warner (1995). A country is considered to be open if it meets minimum criteria on four aspects of trade } \\
\text { policy: average tariffs must be lower than } 40 \text { percent, quotas and licensing must cover less than } 40 \\
\text { percent of total imports, the black market premium must be less than } 20 \text { percent, and export taxes } \\
\text { should be moderate. }\end{array}$ & Gallup et al. (1999) \\
\hline CTRADE & Natural log of the Frankel-Romer measure of predisposition to external trade & Frankel and Romer (1999) \\
\hline EXPMANU & Dummy for manufactured good exporting countries & $\begin{array}{l}\text { Global Development Network } \\
\text { Database in World Bank } \\
\text { (GDN), } 2002\end{array}$ \\
\hline EXPPRIM & Dummy for fuel, non-fuel primary good exporting countries & $\begin{array}{l}\text { Global Development Network } \\
\text { Database in World Bank } \\
\text { (GDN), } 2002\end{array}$ \\
\hline
\end{tabular}


SDBMP

SDTP

SDTT

$\underline{\text { Institutional variables }}$

COMLEG

CIVLEG

POLITY2

DURABLE

FREE
Standard deviation of annual black market premium (BMP), 1960-89

Standard deviation of trading partners' GDP per capita growth (\% weighted average by trade share).

Standard deviation of the first log-differences of a terms of trade index for goods and services.

The dummy for British legal origin

Legal origin dummy for French, German and Scandinavian

Index of democracy. It is called combined polity score, the democracy score minus the autocracy score. The democracy and autocracy scores are derived from the six authority characterics (regulation, competitiveness and openness of executive recruitment; operational independence of chief executive or executive constraints; and regulation and competition of participation). Based on these criterion, each country is assigned a democracy score and autocracy score ranging from 0 to 10, accordingly, the POLITY2 ranges from -10 to 10 with higher values representing more democratic regimes. averaged over 1960-89.

Index of political stability based on the number of years since the last (3-point or greater) regime transition, averaged over 1960-89.

PolityIV Database (Marshall et al, 2003)

The average of indexes of civil liberites and political rights over 1972-89. The basic components of the

Freedom House $(\mathrm{FH})$

index of civil liberites are (1) freedom of expression and belief, (2) association and organizational rights, www.freedomhouse.org, 2003 (3) rule of law and human rights, (4) personal autonomy and economic rights. Rescaled from zero to one, with higher values indicating better civil liberties. The basic components of the index of political rights are (1) free and fair elections; (2) those elected rule; (3) there are competitive parties or other competitive political groupings; (4) the opposition has an important role and power; (5) the entities have self-determination or an extremely high degree of autonomy." Rescaled from zero to one, with higher values indicating better political rights.

Average of six measures of institutional development: voice and accountability, political stability and absence of violence, government effectiveness, light regulatory burden, rule of law, and freedom from graft.

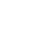

World Development

Indicators (WDI), 2004

GDN

GDN

GDN

GDN 
EURO1900

MEDSHARE

SRIGHT

CRIGHT

\section{Geographic variable}

\section{REGEAP}

REGMENA

REGSA

REGSSA
Political Constraints Index is a structurally derived measure of the feasibility of policy change (the extent to which a change in the preferences of any one actor may lead to a change in government policy).

The percent of population that was European or European descent in 1900.

The index of media owned by the government, the average of the market share of state-owned newspapers and state-owned television stations. Market share of state-owned newspapers is the market share owned by the state out of the aggregate market share of the five largest daily newspapers (by circulation). Market share of state-owned television stations is the market share owned by the state out of the aggregate market share of the five largest television stations (by viewership)

An index aggregating the shareholder rights which we labeled as "anti-director rights." The index is formed by adding 1 when: (1) the country allows shareholders to mail their proxy vote to the firm; (2) shareholders are not required to deposit their shares prior to the General Shareholders' Meeting; (3) cumulative voting or proportional representation of minorities in the board of directors is allowed; (4) an oppressed minorities mechanism is in place; (5) the minimum percentage of share capital that entitles a shareholder to call for an Extraordinary Shareholders' Meeting is less than or equal to 10 percent (the sample median); or (6) shareholders have preemptive rights that can only be waved by a shareholders' vote. The index ranges from 0 to 6.

An index aggregating creditor rights. The index is formed by adding 1 when: (1) the country imposes restrictions, such as creditors' consent or minimum dividends, to file for reorganization; (2) secured creditors are able to gain possession of their security once the reorganization petition has been approved (no automatic stay); (3) the debtor does not retain the administration of its property pending the resolution of the reorganization; (4) secured creditors are ranked first in the distribution of the proceeds that result from the disposition of the assets of a bankrupt firm. The index ranges from 0 to 4 .
Henisz (2000), 2002 version

Acemoglu et al (2001)

Djankov et al. (2003)

La Porta et al. (1998)

La Porta et al. (1998)

GDN

GDN

GDN

Region dummy for South Asian countries

GDN 
REGLAC

REGWENA

LANDLOCK

LATUTUDE

AREA

POP100CR

MINDIST

RESPOINT

Other variables

GDP90

POP90

ETHPOL

ETHNIC

RELIGION

LANGUAGE

ERUFRAC

INCLOW

INCMID

INCHIGH
Region dummy for Latin America and Caribbean countries

GDN

Region dummy for West Europe and North American countries

GDN

Dummy for landlocked countries

GDN

Latitude--absolute distance from equator

Area (in log) in square kilometers from World Bank (1997), except for Taiwan and Mexico from CIA (1997), with submerged land subtracted out.

Proportion of the population in 1994 within $100 \mathrm{~km}$ of the coastline or ocean-navigable river.

The log of minimum distance from three capital-goods-supplying centres plus one.

Dummy for point source exporting countries.

GDN

Gallup et al. (1999)

Gallup et al. (1999)

Jon Haveman's International trade data. www.eiit.org

Isham et al (2002)

Log of real GDP per capita (chain) in 1990

PWT61

PWT61

Reynal-Querol and Montalvo (2005)

Alesina et al.(2003)

Index of ethnic fractionalization

Index of religious fractionalization

Alesina et al.(2003)

Alesina et al.(2003)

Index of language fractionalization

Hall and Jones (1999)

the major languages of Western Europe: English, French, German, Portuguese, or Spanish.

low income countries

GDN

GDN

upper middle and lower-middle income countries

high income OECD and non-OECD countries
GDN 


\section{Appendix Table 2: Descriptive Statistics}

Geography

\begin{tabular}{l|lllllll}
\hline & FD & LANDLOCK & LATITUDE & AREA & MINDIST & POP100CR RESPOINT \\
\hline FD & 1.000 & & & & & & \\
LANDLOCK & -0.163 & 1.000 & & & & & \\
LATITUDE & 0.536 & -0.059 & 1.000 & & & & \\
AREA & -0.095 & -0.009 & 0.096 & 1.000 & & & \\
MINDIST & -0.514 & 0.121 & -0.503 & 0.007 & 1.000 & & \\
POP100CR & 0.376 & -0.583 & 0.293 & -0.429 & -0.340 & 1.000 & \\
RESPOINT & -0.387 & 0.027 & -0.296 & 0.108 & 0.252 & -0.215 & 1.000 \\
\hline
\end{tabular}

Institution

\begin{tabular}{|c|c|c|c|c|c|c|c|c|c|c|}
\hline & FD & TOPEN & CTRADE & EXPMANU & EXPPRIM & SDGR & SDBMP & SDPI & SDTP & SDTT \\
\hline$\overline{F D}$ & 1.000 & & & & & & & & & \\
\hline TOPEN & 0.660 & 1.000 & & & & & & & & \\
\hline CTRADE & 0.196 & 0.207 & 1.000 & & & & & & & \\
\hline EXPMANU & 0.447 & 0.429 & 0.039 & 1.000 & & & & & & \\
\hline EXPPRIM & -0.463 & -0.482 & -0.131 & -0.320 & 1.000 & & & & & \\
\hline SDGR & -0.321 & -0.359 & 0.213 & -0.199 & 0.461 & 1.000 & & & & \\
\hline SDBMP & -0.142 & -0.092 & -0.016 & -0.063 & 0.122 & 0.121 & 1.000 & & & \\
\hline SDPI & -0.086 & -0.017 & -0.049 & -0.056 & 0.189 & 0.047 & 0.716 & 1.000 & & \\
\hline SDTP & -0.112 & -0.130 & -0.108 & 0.050 & 0.113 & 0.077 & 0.164 & 0.139 & 1.000 & \\
\hline SDTT & -0.411 & -0.424 & -0.133 & -0.181 & 0.415 & 0.388 & 0.116 & 0.060 & 0.060 & 1.000 \\
\hline
\end{tabular}

\section{Policy}

\begin{tabular}{l|llllllll}
\hline & FD & CIVLEG & COMLEG & POLITY2 & DURABLE & FREE & KKZ & PCI \\
\hline FD & 1.000 & & & & & & & \\
CIVLEG & -0.071 & 1.000 & & & & & & \\
COMLEG & 0.037 & -0.942 & 1.000 & & & & & \\
POLITY2 & 0.325 & -0.255 & 0.319 & 1.000 & & & & \\
DURABLE & 0.451 & -0.131 & 0.111 & 0.429 & 1.000 & & & \\
FREE & -0.374 & -0.002 & -0.088 & -0.725 & -0.474 & 1.000 & & \\
KKZ & 0.675 & 0.050 & -0.018 & 0.525 & 0.506 & -0.711 & 1.000 & \\
PCI & 0.318 & 0.032 & 0.031 & 0.722 & 0.404 & -0.892 & 0.644 & 1.000 \\
\hline
\end{tabular}

Others

\begin{tabular}{|c|c|c|c|c|c|c|c|c|}
\hline & FD & GDP90 & POP90 & ETHPOL & ETHNIC & RELIGION & \multicolumn{2}{|c|}{ LANGUAG EURFRAC } \\
\hline$\overline{F D}$ & 1.000 & & & & & & & \\
\hline GDP90 & 0.627 & 1.000 & & & & & & \\
\hline OPO90 & 0.070 & -0.014 & 1.000 & & & & & \\
\hline ETHPOL & -0.169 & -0.178 & -0.107 & 1.000 & & & & \\
\hline ETHNIC & -0.358 & -0.516 & -0.006 & 0.540 & 1.000 & & & \\
\hline RELIGION & 0.151 & -0.103 & -0.030 & 0.207 & 0.231 & 1.000 & & \\
\hline LANGUAGE & -0.159 & -0.463 & 0.084 & 0.294 & 0.673 & 0.268 & 1.000 & \\
\hline EURFRAC & -0.082 & 0.346 & -0.060 & 0.154 & -0.138 & 0.081 & -0.462 & 1.000 \\
\hline
\end{tabular}




\section{Appendix Table 3: The list of countries in the full sample}

\begin{tabular}{|c|c|c|c|c|c|}
\hline \multicolumn{2}{|c|}{ East Asia \& Pacific } & \multicolumn{2}{|c|}{ Middle East \& North Africa } & \multicolumn{2}{|c|}{ South Asia } \\
\hline AUS & Australia & BHR & Bahrain & BGD & Bangladesh \\
\hline $\mathrm{CHN}$ & China & DZA & Algeria & IND & India \\
\hline FJI & Fiji & EGY & Egypt, Arab Rep. & LKA & Sri Lanka \\
\hline HKG & Hong Kong, China & GRC & Greece & NPL & Nepal \\
\hline IDN & Indonesia & IRN & Iran, Islamic Rep. & PAK & Pakistan \\
\hline JPN & Japan & ISR & Israel & & \\
\hline KOR & Korea, Rep. & JOR & Jordan & & \\
\hline MAC & Macao & KWT & Kuwait & & \\
\hline MNG & Mongolia & LBN & Lebanon & & \\
\hline MYS & Malaysia & MAR & Morocco & & \\
\hline NZL & New Zealand & MLT & Malta & & \\
\hline PHL & Philippines & $\mathrm{OMN}$ & Oman & & \\
\hline PNG & Papua New Guinea & PRT & Portugal & & \\
\hline SGP & Singapore & QAT & Qatar & & \\
\hline THA & Thailand & SAU & Saudi Arabia & & \\
\hline TWN & Taiwan, China & TUN & Tunisia & & \\
\hline VNM & Vietnam & & & & \\
\hline \multicolumn{2}{|c|}{ Sub Sahara Africa } & \multicolumn{2}{|c|}{ Latin America \& Caribbean } & \multicolumn{2}{|c|}{ West Europe \& North America } \\
\hline BDI & Burundi & ARG & Argentina & AUT & Austria \\
\hline BEN & Benin & BOL & Bolivia & BEL & Belgium \\
\hline BFA & Burkina Faso & BRA & Brazil & CAN & Canada \\
\hline BWA & Botswana & $\mathrm{BRB}$ & Barbados & $\mathrm{CHE}$ & Switzerland \\
\hline CIV & Cote d'Ivoire & $\mathrm{CHL}$ & Chile & CYP & Cyprus \\
\hline CMR & Cameroon & $\mathrm{COL}$ & Colombia & DEU & Germany \\
\hline ETH & Ethiopia & CRI & Costa Rica & DNK & Denmark \\
\hline GHA & Ghana & $\mathrm{DOM}$ & Dominican Republic & ESP & Spain \\
\hline KEN & Kenya & ECU & Ecuador & FIN & Finland \\
\hline MDG & Madagascar & GTM & Guatemala & FRA & France \\
\hline MLI & Mali & GUY & Guyana & GBR & United Kingdom \\
\hline MOZ & Mozambique & HND & Honduras & IRL & Ireland \\
\hline MRT & Mauritania & HTI & Haiti & ISL & Iceland \\
\hline MUS & Mauritius & JAM & Jamaica & ITA & Italy \\
\hline MWI & Malawi & MEX & Mexico & LUX & Luxembourg \\
\hline NAM & Namibia & NIC & Nicaragua & NLD & Netherlands \\
\hline NGA & Nigeria & PAN & Panama & NOR & Norway \\
\hline RWA & Rwanda & PER & Peru & SWE & Sweden \\
\hline SDN & Sudan & PRY & Paraguay & USA & United States \\
\hline SEN & Senegal & SLV & El Salvador & & \\
\hline SLE & Sierra Leone & TTO & Trinidad and Tobago & & \\
\hline SWZ & Swaziland & URY & Uruguay & & \\
\hline TGO & Togo & VEN & Venezuela & & \\
\hline UGA & Uganda & & & & \\
\hline ZAF & South Africa & & & & \\
\hline $\mathrm{ZMB}$ & Zambia & & & & \\
\hline ZWE & Zimbabwe & & & & \\
\hline
\end{tabular}


Appendix Table 4. The eigenvalue, proportion and eigenvector of each first principal component.

\begin{tabular}{|c|c|c|c|c|c|c|c|c|c|c|}
\hline Measure & Eigenvalue & Proportion & LLY & PRIVO & 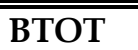 & $\overline{\mathrm{OVC}}$ & "NIM & MCAP & $\overline{\mathrm{TVT}}$ & $\overline{\overline{\text { TOR }}}$ \\
\hline FD & 3.922 & 0.490 & 0.411 & 0.454 & 0.278 & -0.357 & -0.368 & 0.364 & 0.357 & 0.157 \\
\hline FDBANK & 3.063 & 0.613 & 0.479 & 0.479 & 0.357 & -0.437 & -0.471 & & & \\
\hline FDSTOCK & 1.986 & 0.662 & & & & & & 0.535 & 0.676 & 0.506 \\
\hline FDEFF & 2.160 & 0.540 & & & & 0.546 & 0.561 & & -0.467 & -0.411 \\
\hline FDSIZE & 1.612 & 0.806 & 0.707 & & & & & 0.707 & & \\
\hline
\end{tabular}

Notes: The financial development measures are described in Table 1. The first principal component is the linear combination of the measures selected. The eigenvalues are the variances of the (first) principal components. The eigenvectors give the coefficients of the standardised variables.

LLY = the ratio of liquid liabilities of financial system (currency plus demand and interest-bearing liabilities of banks and nonbanks) to GDP;

$\mathrm{PRIVO}=$ the ratio of credits issued to private sector by banks and other financial intermediaries to GDP;

$\mathrm{OVC}=$ the ratio of overhead costs to total assets of the banks; NIM = the bank interest income minus interest expense over total assets;

$\mathrm{MCAP}=$ the ratio of the value of domestic shares traded on domestic exchange to GDP;

TVT $=$ the ratio of the value of domestic shares traded on domestic exchange to GDP;

$\mathrm{TOR}=$ the ratio of the value of domestic shares traded on domestic exchange to total value of listed domestic shares 


\section{Appendix Table 5: Imputation}

\begin{tabular}{|c|c|c|c|c|c|c|c|c|c|c|c|c|}
\hline Variables & Variable & used to imp & ute the mis & ing data & & & & & & & & \\
\hline ETHPOL & REGEAP & REGMENA & REGSA & REGSSA & REGLAC & REGWENA & RELIGION & & & & & \\
\hline ETHNIC & REGEAP & REGMENA & REGSA & REGSSA & REGLAC & REGWENA & RELIGION & & & & & \\
\hline LANGUAGE & REGEAP & REGMENA & REGSA & REGSSA & REGLAC & REGWENA & RELIGION & & & & & \\
\hline EURFRAC & REGEAP & REGMENA & REGSA & REGSSA & REGLAC & REGWENA & RELIGION & & & & & \\
\hline CTRADE & REGEAP & REGMENA & REGSA & REGSSA & REGLAC & REGWENA & INCLOW & INCMID & INCHIGH & EXPMANU & EXPPRIM & LANDLOCK \\
\hline TOPEN & REGEAP & REGMENA & REGSA & REGSSA & REGLAC & REGWENA & INCLOW & INCMID & INCHIGH & EXPMANU & EXPPRIM & LANDLOCK \\
\hline AREA & REGEAP & REGMENA & REGSA & REGSSA & REGLAC & REGWENA & LANDLOCK & LATITUDE & & & & \\
\hline MINDIST & REGEAP & REGMENA & REGSA & REGSSA & REGLAC & REGWENA & LANDLOCK & LATITUDE & & & & \\
\hline POP100CR & REGEAP & REGMENA & REGSA & REGSSA & REGLAC & REGWENA & LANDLOCK & LATITUDE & & & & \\
\hline POP90 & REGEAP & REGMENA & REGSA & REGSSA & REGLAC & REGWENA & LANDLOCK & & & & & \\
\hline RESPOINT & REGEAP & REGMENA & REGSA & REGSSA & REGLAC & REGWENA & LANDLOCK & LATITUDE & & & & \\
\hline POLITY2 & CIVLEG & COMLEG & LATITUDE & & & & & & & & & \\
\hline DURABLE & CIVLEG & COMLEG & LATITUDE & & & & & & & & & \\
\hline FREE & CIVLEG & COMLEG & LATITUDE & & & & & & & & & \\
\hline KKZ & CIVLEG & COMLEG & LATITUDE & & & & & & & & & \\
\hline PCI & CIVLEG & COMLEG & LATITUDE & & & & & & & & & \\
\hline EURO1900 & CIVLEG & COMLEG & LATITUDE & REGEAP & REGMENA & REGSA & REGSSA & REGLAC & REGWENA & & & \\
\hline SRIGHT & CIVLEG & COMLEG & LATITUDE & & & & & & & & & \\
\hline CRIGHT & CIVLEG & COMLEG & LATITUDE & & & & & & & & & \\
\hline MEDSHARE & CIVLEG & COMLEG & LATITUDE & & & & & & & & & \\
\hline GDP90 & INCLOW & INCMID & INCHIGH & REGEAP & REGMENA & REGSA & REGSSA & REGLAC & REGWENA & LATITUDE & & \\
\hline SDGR & INCLOW & INCMID & INCHIGH & REGEAP & REGMENA & REGSA & REGSSA & REGLAC & REGWENA & LATITUDE & & \\
\hline SGBMP & INCLOW & INCMID & INCHIGH & CIVLEG & COMLEG & LATITUDE & & & & & & \\
\hline SDPI & INCLOW & INCMID & INCHIGH & CIVLEG & COMLEG & LATITUDE & & & & & & \\
\hline SDTP & INCLOW & INCMID & INCHIGH & REGEAP & REGMENA & REGSA & REGSSA & REGLAC & REGWENA & LATITUDE & & \\
\hline SDTT & INCLOW & INCMID & INCHIGH & REGEAP & REGMENA & REGSA & REGSSA & REGLAC & REGWENA & LATITUDE & & \\
\hline
\end{tabular}


Appendix Table 6: Setting for PcGets

\begin{tabular}{|c|c|c|c|c|c|c|c|c|}
\hline expert significance: & 0.075 & 0.075 & 0.75 & 0.075 & 0.01 & 0.005 & & \\
\hline expert presearch: & 0.75 & 1 & 0.5 & 0.075 & 0.075 & 0.05 & 0.05 & 1 \\
\hline expert block search: & 1 & 1 & 1 & 1 & 1 & 1 & 1 & 1 \\
\hline expert choose specific: & & "hq" & & & & & & \\
\hline expert split sample: & 0.075 & 0.75 & 0.2 & 0.4 & 0.4 & & & \\
\hline expert outlier dection: & & 2.56 & & & & & & \\
\hline expert tests: & 1 & 1 & 0 & 1 & 0 & 0 & 1 & \\
\hline expert test options: & 0.5 & 0.9 & 12 & 1 & 4 & 1 & 4 & \\
\hline set detect outliers: & "1" & & & & & & & \\
\hline set0lagorder: & "0" & & & & & & & \\
\hline set0topdown: & "1" & & & & & & & \\
\hline set0bottomup: & "1" & & & & & & & \\
\hline setsplitsample: & "1" & & & & & & & \\
\hline setstrategy: & "expert", & 1 & & & & & & \\
\hline setreporting: & "0" & & & & & & & \\
\hline estimate: & "GETS", & 1 & 1 & $\mathrm{n}$ & 1 & & "n" denotes & ample size) \\
\hline
\end{tabular}

Note: A change has been made to the "liberal strategy" default setting by increasing the F pre-search testing (top-down) at step 1 from 0.75 to 1 . 
Appendix Table 7. Determinants of FD by using PcGets

\begin{tabular}{|c|c|c|c|c|c|c|c|c|c|c|c|c|}
\hline \multirow{3}{*}{$\begin{array}{l}\text { Sample } \\
\text { Model } \\
\text { Variable }\end{array}$} & \multicolumn{4}{|c|}{ Full Sample } & \multicolumn{4}{|c|}{ Developing Country Sample } & \multicolumn{4}{|c|}{ La Porta Sample } \\
\hline & \multirow{2}{*}{ Coeff } & \multirow{2}{*}{$\begin{array}{l}\text { GUM } \\
\text {--value }\end{array}$} & \multicolumn{2}{|c|}{ Final Model } & \multicolumn{2}{|c|}{ GUM } & \multicolumn{2}{|c|}{ Final Model } & \multicolumn{2}{|c|}{ GUM } & \multicolumn{2}{|c|}{ Final Model } \\
\hline & & & Coeff & t-value & Coeff & $\mathrm{t}$-value & Coeff & t-value & Coeff & t-value & Coeff & t-value \\
\hline CONSTANT & -8.112 & -1.338 & -10.563 & -4.074 & -16.154 & -1.151 & -15.723 & -5.932 & 0.000 & 0.000 & & \\
\hline GDP90 & 1.326 & 2.660 & 1.391 & 4.403 & 2.250 & 2.823 & 2.049 & 7.192 & -0.878 & -0.316 & & \\
\hline POP90 & 0.566 & 2.549 & 0.705 & 5.856 & 0.768 & 1.816 & 0.248 & 2.855 & 1.044 & 1.733 & 1.314 & 8.610 \\
\hline ETHPOL & 0.497 & 0.511 & & & -1.290 & -0.671 & & & 2.592 & 0.672 & 3.131 & 4.652 \\
\hline ETHNIC & -0.774 & -0.557 & & & 0.282 & 0.137 & & & 0.111 & 0.032 & & \\
\hline RELIGION & -0.214 & -0.188 & & & -0.386 & -0.156 & & & 2.183 & 0.400 & & \\
\hline LANGUAGE & 1.132 & 1.138 & & & 2.920 & 1.847 & 1.487 & 2.941 & 1.469 & 0.492 & & \\
\hline EURFRAC & -0.702 & -0.940 & -1.287 & -3.694 & 2.010 & 0.797 & & & -4.480 & -2.036 & -3.988 & -6.216 \\
\hline REGEAP & 0.938 & 0.659 & & & 1.486 & 0.334 & & & -4.249 & -0.841 & -4.224 & -3.847 \\
\hline REGMENA & 0.798 & 0.600 & & & 5.417 & 1.011 & 3.353 & 7.548 & -0.477 & -0.104 & & \\
\hline REGSA & 0.311 & 0.227 & & & 2.864 & 0.457 & & & -4.670 & -0.853 & -3.000 & -4.524 \\
\hline REGSSA & -0.275 & -0.178 & & & 1.664 & 0.309 & & & -1.473 & -0.193 & & \\
\hline REGLAC & 0.029 & 0.022 & & & 0.275 & 0.079 & & & 3.615 & 1.283 & 2.435 & 3.317 \\
\hline REGWENA & -0.388 & -0.262 & & & & & & & -9.044 & -1.455 & -7.789 & -5.614 \\
\hline LANDLOCK & -0.266 & -0.325 & & & 1.098 & 0.772 & & & 2.585 & 1.188 & 2.562 & 3.979 \\
\hline LATITUDE & -0.021 & -0.805 & -0.041 & -2.948 & -0.046 & -1.241 & & & 0.071 & 0.644 & & \\
\hline AREA & -0.421 & -2.383 & -0.417 & -4.188 & -0.246 & -0.725 & & & -0.260 & -0.564 & -0.416 & -4.095 \\
\hline MINDIST & -0.036 & -0.258 & & & -0.272 & -0.183 & & & -0.232 & -0.508 & & \\
\hline POP100CR & -0.010 & -0.824 & & & 0.010 & 0.726 & & & 0.015 & 0.471 & 0.015 & 2.592 \\
\hline RESPOINT & -0.269 & -0.500 & & & -0.774 & -0.916 & 3.353 & 7.548 & -3.148 & -1.723 & -2.960 & -4.633 \\
\hline TOPEN & 0.608 & 0.712 & & & 2.046 & 1.220 & 1.990 & 5.192 & 3.184 & 1.237 & 1.854 & 3.512 \\
\hline CTRADE & 0.013 & 0.640 & & & 0.036 & 1.495 & & & 0.046 & 0.487 & 0.034 & 2.421 \\
\hline EXPMANU & -0.097 & -0.198 & & & -1.975 & -0.349 & & & 0.848 & 0.958 & 1.246 & 4.264 \\
\hline EXPPRIM & -0.378 & -0.792 & & & 0.362 & 0.478 & & & 1.844 & 1.164 & 1.416 & 2.597 \\
\hline SDGR & -0.026 & -0.203 & & & -0.126 & -0.636 & & & -0.794 & -1.154 & -0.571 & -3.875 \\
\hline SDBMP & 0.000 & -0.631 & & & -0.001 & -1.315 & & & 0.004 & 1.485 & 0.004 & 4.876 \\
\hline SDPI & 0.001 & 1.273 & & & 0.001 & 1.053 & 0.001 & 2.193 & -0.031 & -1.513 & -0.035 & -5.076 \\
\hline SDTP & 0.120 & 0.232 & & & -0.435 & -0.519 & & & -2.270 & -0.825 & -1.390 & -2.263 \\
\hline SDTT & -0.008 & -0.805 & -0.024 & -3.270 & -0.015 & -0.720 & & & 0.033 & 0.827 & 0.036 & 3.222 \\
\hline CIVLEG & -2.353 & -1.307 & -0.927 & -3.396 & -6.899 & -1.458 & -4.562 & -5.239 & 10.563 & 0.332 & & \\
\hline COMLEG & -1.885 & -1.037 & & & -5.840 & -1.083 & -3.445 & -3.879 & 12.554 & 0.390 & 1.687 & 4.452 \\
\hline POLITY2 & 0.051 & 0.927 & & & 0.151 & 1.528 & 0.164 & 4.382 & 0.083 & 0.326 & & \\
\hline DURABLE & 0.014 & 0.903 & & & -0.025 & -0.781 & & & 0.010 & 0.248 & & \\
\hline FREE & 0.001 & 0.004 & & & 0.168 & 0.596 & & & -0.542 & -0.424 & -0.453 & -3.033 \\
\hline KKZ & 1.191 & 1.974 & 1.846 & 5.064 & 0.099 & 0.119 & & & 3.425 & 1.245 & 4.849 & 9.156 \\
\hline PCI & -4.827 & -2.095 & -5.363 & -5.184 & -6.769 & -1.870 & -5.391 & -4.026 & -13.777 & -1.472 & -13.547 & -7.002 \\
\hline EURO1900 & & & & & 3.579 & 0.633 & & & & & & \\
\hline MEDSHARE & & & & & & & & & 0.627 & 0.152 & & \\
\hline SRIGHT & & & & & & & & & -0.282 & -0.320 & & \\
\hline CRIGHT & & & & & & & & & -0.413 & -1.098 & -0.374 & -3.169 \\
\hline RSS & & 26.44 & & 51.11 & & 5.37 & & 17.06 & & 1.03 & & 3.78 \\
\hline sigma & & 0.97 & & 0.97 & & 0.82 & & 0.73 & & 1.02 & & 0.50 \\
\hline $\mathrm{R}^{\wedge} 2$ & & 0.90 & & 0.80 & & 0.96 & & 0.86 & & 0.99 & & 0.98 \\
\hline $\operatorname{Radj}^{\wedge} 2$ & & 0.77 & & 0.77 & & 0.77 & & 0.82 & & 0.77 & & 0.94 \\
\hline LogLik & & 28.28 & & 7.20 & & 46.26 & & 20.84 & & 73.12 & & 47.21 \\
\hline AIC & & 0.24 & & 0.09 & & -0.47 & & -0.40 & & -1.71 & & -1.11 \\
\hline HQ & & 0.72 & & 0.22 & & 0.08 & & -0.22 & & -1.11 & & -0.73 \\
\hline SC & & 1.46 & & 0.42 & & 0.99 & & 0.08 & & -0.06 & & -0.05 \\
\hline Chow test 1 & 0.00 & 0.00 & & & 0.00 & 0.00 & & & 0.00 & 0.00 & & \\
\hline Chow test 2 & 1.34 & 0.28 & 0.66 & 0.68 & 7.45 & 0.39 & 1.35 & 0.28 & 0.00 & 0.00 & & \\
\hline $\begin{array}{l}\text { Normality tes } \\
\text { Hetero test }\end{array}$ & 0.17 & 0.92 & 8.46 & 0.01 & 1.77 & 0.41 & 1.76 & 0.41 & 2.59 & 0.27 & 1.35 & 0.51 \\
\hline
\end{tabular}

Note: The dependent variable FD is the index of overall financial development over period, 1990-99. The variable

description is in Appendix Table 1. The PcGets analysis yields coefficient and $t$-value for the variables in the final model.

There are 64 observations in the whole sample, 44 observations in the developing country sample and 40 observations in the

La Porta sample. 


\section{Appendix Table 8. Determinants of FDBOND}

\begin{tabular}{|c|c|c|c|c|}
\hline \multirow{3}{*}{$\begin{array}{l}\text { Sample } \\
\text { Method } \\
\text { Variable }\end{array}$} & \multicolumn{4}{|c|}{ La Porta's Dataset } \\
\hline & \multicolumn{2}{|c|}{ BMA } & \multicolumn{2}{|c|}{ PcGets } \\
\hline & PIPS & Sign & Coeff & t-value \\
\hline CONSTANT & 1.000 & $(-)$ & -6.273 & -4.754 \\
\hline GDP90 & 0.678 & $(+)$ & 0.648 & 4.481 \\
\hline POP90 & 0.007 & & & \\
\hline \multicolumn{5}{|l|}{ ETHPOL } \\
\hline \multicolumn{5}{|l|}{ ETHNIC } \\
\hline \multicolumn{5}{|l|}{ RELIGION } \\
\hline LANGUAGE & 0.634 & $(+)$ & 0.855 & 3.939 \\
\hline EURFRAC & 0.127 & & & \\
\hline REGEAP & 0.665 & $(-)$ & -0.529 & -4.297 \\
\hline \multicolumn{5}{|l|}{ REGMENA } \\
\hline REGSA & 0.024 & & & \\
\hline REGSSA & 0.245 & $(+)$ & & \\
\hline \multicolumn{5}{|l|}{ REGLAC } \\
\hline REGWENA & 0.122 & & & \\
\hline LANDLOCK & 0.012 & & & \\
\hline \multicolumn{5}{|l|}{ LATITUDE } \\
\hline \multicolumn{5}{|l|}{ AREA } \\
\hline MINDIST & 0.424 & $(-)$ & & \\
\hline POP100CR & 0.663 & $(+)$ & 0.011 & 3.820 \\
\hline RESPOINT & 0.087 & & & \\
\hline TOPEN & 0.236 & $(+)$ & & \\
\hline \multicolumn{5}{|l|}{ CTRADE } \\
\hline EXPMANU & 0.013 & & & \\
\hline EXPPRIM & 0.000 & & & \\
\hline SDGR & 0.062 & & & \\
\hline SDBMP & 0.000 & & & \\
\hline SDPI & 0.026 & & & \\
\hline SDTP & 0.022 & & & \\
\hline SDTT & 0.628 & $(+)$ & 0.018 & 2.906 \\
\hline \multicolumn{5}{|l|}{ CIVLEG } \\
\hline COMLEG & 0.012 & & & \\
\hline POLITY2 & 0.032 & & & \\
\hline DURABLE & 0.108 & & & \\
\hline FREE & 0.019 & & & \\
\hline KKZ & 0.620 & $(-)$ & -0.345 & -2.642 \\
\hline PCI & 0.781 & $(+)$ & & \\
\hline \multicolumn{5}{|l|}{ EURO1900 } \\
\hline MEDSHARE & 0.022 & & & \\
\hline SRIGHT & 0.135 & & & \\
\hline CRIGHT & 0.161 & & & \\
\hline \multicolumn{3}{|l|}{ RSS } & & 1.76 \\
\hline \multicolumn{3}{|l|}{ sigma } & & 0.25 \\
\hline \multicolumn{3}{|l|}{$\mathrm{R}^{\wedge} 2$} & & 0.69 \\
\hline \multicolumn{3}{|l|}{$\operatorname{Radj}^{\wedge} 2$} & & 0.62 \\
\hline \multicolumn{3}{|l|}{ LogLik } & & 52.37 \\
\hline AIC & & & & -2.59 \\
\hline HQ & & & & -2.48 \\
\hline SC & & & & -2.28 \\
\hline Chow test 1 & & & & \\
\hline Chow test 2 & & & 1.49 & 0.24 \\
\hline Normality test & & & 3.79 & 0.15 \\
\hline Hetero test & & & & \\
\hline
\end{tabular}

Note: The dependent variable FDBOND is the index of bond market development over period, 1990-99. The variable description is in Appendix Table 1. This study is based on La Porta dataset with 35 countries. The BMA analysis yields posterior probabilities of inclusion (PIPs), the total posterior model probabilities for all models including a given variable, and the sign certainty index of a relationship (Sign). No sign given means the sign of estimated relationship being uncertain.each variable. The PcGets analysis yields coefficient and $\mathrm{t}$-value for the variables in the final model. 